Spal I at i on occur rence from pol yami de materi al s i r r adi at ed by ther mal pl asma wi th water absor pt i on

\begin{tabular}{|l|l|}
\hline 著者 & $\begin{array}{l}\text { Nakano Tomøyuki, Tanaka Yasunor i, Nakagawa } \\
\text { Takuya, Shi nsei Naoki ., Uesugi Yoshi hi ko, } \\
\text { I shi j i ma Tat suo }\end{array}$ \\
\hline $\begin{array}{l}\text { j our nal or } \\
\text { publ i cat i on ti tl e }\end{array}$ & Journal of Physi cs D: Appl i ed Physi cs \\
\hline vol une & 49 \\
\hline nunber & 38 \\
\hline page range & 385501 \\
\hline year & $2016-08$ 23 \\
\hline URL & ht t p: //hdl . handl e. net /2297/46506 \\
\hline
\end{tabular}




\title{
Spallation occurrence from polyamide materials irradiated by thermal plasma with water absorption
}

\author{
Tomoyuki Nakanoł, Yasunori Tanakał, T Nakagawa, N Shinsei, \\ Y Uesugi, T Ishijima \\ Division of Electrical Engineering and Computer Science, Kanazawa University, \\ Kakuma, Kanazawa 920-1192, Japan \\ E-mail: tnakano@stu.kanazawa-u.ac.jp, tanaka@ec.t.kanazawa-u.ac.jp
}

\begin{abstract}
This paper first describes the effect of water absorption to polyamide material irradiated by thermal plasmas on the occurrence of spallation phenomena. Interaction between polyamide materials and arc plasmas occurs particularly in low voltage circuit breaker and aerospace fields. Spallation phenomena are those in which polymer particles are ejected from polymer bulk materials irradiated by high heat flux. To confirm the effect of water absorption into polyamide material on spallation phenomena, polyamide specimens with and without water absorption were irradiated by Ar inductively coupled thermal plasma (ICTP). Results show that the polyamide specimen with water absorption ejected spallation particles, whereas the polyamide specimen without water absorption were only slightly ejected, indicating that water absorption promotes spallation occurrence. Furthermore, molecular gas inclusions such as $\mathrm{N}_{2}$ and $\mathrm{O}_{2}$ irradiated by thermal plasmas enhance spallation phenomena. Cooling effects of spallation polyamide 66 (PA66) particles ablation were also estimated in hot air to assess the arc quenching ability from the spallation particle inclusion. This estimation showed that 10 and more PA66 particles inclusion might decrease the air temperature by $3000 \mathrm{~K}$ effectively, which can be useful to enhance arc quenching in circuit breakers working in air.
\end{abstract}

Submitted to: J. Phys. D: Appl. Phys.

$\nmid$ To whom correspondence should be addressed (tnakano@stu.kanazawa-u.ac.jp)

$\ddagger$ To whom correspondence should be addressed (tanaka@ec.t.kanazawa-u.ac.jp) 


\section{Introduction}

Direct current $(\mathrm{dc})$ power transmission and distribution systems are receiving attention worldwide because the electric devices of today work with inverter power supplies which convert commercially transmitted ac current to dc current and then to high-frequency current. Direct current is also used for electric vehicles (EV), power conditioners, and electronic devices. In addition, recent progress of 'smart grids' is gradually increasing the electric power to be handled. The dc system described above requires high-performance dc circuit breakers for severe accidents. For the reasons described above, low voltage circuit breakers must be developed to improve arc-quenching and current interruption performance. To enhance the arc-quenching capability of circuit breakers, polymer ablation has been widely adopted. During high-current interruption in a circuit breaker, an arc plasma is formed between the electrodes. The arc plasma contacts the polymer material, which involves strong polymer ablation. The polymer ablation engenders a pressure rise and strong gas flow, resulting in arc cooling. To understand these phenomena, it is necessary to investigate details of the interactions between the polymer and arc plasma / thermal plasma because the interactions are extremely complicated, including thermal decomposition and mixing of vapour and decomposition [1 - 24]

To study interactions between polymer materials and arc plasma / thermal plasma, we used inductively coupled thermal plasma (ICTP) irradiation technique to polymer materials $[25,12]$. The ICTP is irradiated to polymer bulk for this fundamental study of the above interaction instead of arc plasma. In ICTP irradiation experiments, we have pointed out that polyamide materials such as polyamide-6 (PA6) and polyamide66 (PA66) occasionally eject not only ablation gases but also micro-size particles during ICTP irradiation. This particle ejection phenomenon has been named 'spallation' generally in the aerospace field. We expect that such spallation particles can be adopted to enhance the arc quenching ability of a circuit breaker. Spallation particles might penetrate the arc discharge core deeply because of the mass inertia. Subsequently, they will be ablated there to reduce the arc temperature [26, 27].

As described in this paper, first of all, experimentally obtained results of Ar ICTP irradiation tests are presented for polymer materials of seven kinds including PA6 and PA66. Experiment results indicate that the Ar ICTP irradiation involves the occurrence of spallation phenomena only from PA6 and PA66 specimens. This result seems that there must be unique characteristics of PA6 and PA66 related to occurrence of spallation phenomena which were not shown by the other polymer materials in this work. Considering the characteristics of polyamide materials, we inferred that hydrophilia of polyamide might be related to occurrence of spallation. To confirm the relation between hydrophilia of polyamide and spallation occurrence, PA6 and PA66 specimens of two kinds, with and without water absorption, were prepared. Then they were irradiated by Ar ICTP. Results demonstrated that PA6 and PA66 with water absorption ejected much greater quantities of spallation particles than those of without water absorption. In addition, results show that $\mathrm{N}_{2}$ or $\mathrm{O}_{2}$ (contained in air) inclusion to the Ar thermal plasma 
enhances the occurrence of spallation from PA66 with water absorption. Moreover, we estimated the cooling effects of spallation particles in high-temperature air for arc quenching. This method of estimation indicated that inclusion of 10 and more PA66 particles to high-temperature air might cause $3000 \mathrm{~K}$ drop in air temperature, thereby indicating effective arc quenching.

\section{Concept of using induction thermal plasma irradiation technique for investigation of interactions between thermal plasma / arc plasma and polymers}

We used inductively coupled thermal plasma (ICTP) instead of arc plasma between electrodes to investigate interactions between thermal plasma / arc plasma and polymers. This decision can be attributed to our recognition of the following facts: (i) Both the ICTP and the arc plasma between electrodes have extremely high collision frequency among particles, which gives a high heavy-particle temperature approaching the electron temperature. (ii) Their behavior can be described approximately by macroscopic properties such as thermodynamic and transport properties determined by the temperature and the pressure. (iii) Thermal ionization occurs in both an arc and an ICTP to sustain itself with a certain level of electrical conductivity. For these three reasons, both the ICTP and the arc plasma can be categorized as 'thermal plasmas'.

In addition, the ICTP has the following benefits for fundamental investigation: (a) Clean thermal plasma can be produced with no impurities because ICTP needs no electrodes. This fact enables us to investigate fundamental interactions between thermal plasma and polymers. The conventional arcs require electrodes that ablate and contaminate the arc medium, which makes the arc phenomena more complex. (b) The ICTP shows better repeatability in its production, than one-shot circuit-breaker arc testing. (c) Only the polymer species change enables us to compare the effects of polymer varieties that are used.

\section{Thermal plasma irradiation test of various polymer materials}

\subsection{Polymer materials tested}

First of all, thermal plasma irradiation tests for various polymer materials are presented. We have found the spallation occurence from PA6 and PA66. To find a way to control the occurrence of the spallation phenomena, it is important to understand the reason of spallation occurrence from features of base materials. As general polymer materials with simple structures and different characteristics, the following polymer materials were chosen for testing. Polytetrafluoroethylene (PTFE), polyethylene (PE), polyoxymethylene (POM), polymethylmethacrylate (PMMA), polyamide-6 (PA6), polyamide-66 (PA66) and polyformaldehyde (PF).

Table 1 presents a list of the polymer materials tested for Ar-ICTP irradiation. This table presents groups of heat characteristics whether thermoplastic or thermosetting, 
and the decomposition temperature of each polymer. The decomposition temperatures presented here are those which were actually measured using thermogravimetry and differential thermal analysis (TG-DTA) and differential scanning calorimetry (DSC). The PTFE has the highest decomposition temperature among the seven kinds of polymer materials. When the temperature of a polymer material exceeds the decomposition temperature of the polymer, then the polymer is decomposed to eject ablation vapour containing atoms, molecules or ions from the polymer. Such heat decomposition of the polymer can take thermal energy from the heated arc plasma [28]. In the ICTP irradiation test, every polymer is expected to eject ablation vapour. The test may demonstrate that ICTP can be a high-power irradiation source instead of an arc plasma. In addition, it will be clearly seen that spallation phenomena occur only from polyamide materials.

\subsection{Experimental setup and experimental conditions}

Figure 1 depicts the ICTP system used in the present experiment. The ICTP torch comprises two coaxial water-cooled quartz tubes. Each 345-mm-long quartz tube has different diameter, the inner quartz tube has $70 \mathrm{~mm} \phi$ inner diameter. Argon gas is supplied from the top of the plasma torch to the interior of the inner quartz tube as the sheath gas. We can also supply different gases, such as $\mathrm{N}_{2}$ and $\mathrm{O}_{2}$ if we study the effects of chemical reaction of reactive species on interaction between thermal plasma and polymers. An eight-turn induction coil is located around the torch to generate electromagnetic fields. Then inductively coupled thermal plasma is created inside the torch. The generated thermal plasma expands downward below the inlet of the chamber by gas flow. A polymer specimen is embedded in a stainless saucer mounted on a movable specimen holder cooled by flowing water. The shape of polymer specimen used in this experiment is shown in figure 2, which has 15-mm-diameter and $5 \mathrm{~mm}$ thickness. The movable specimen holder can convey the polymer specimen to the position under the thermal plasma flow after the experimental conditions, such as input power, gas flow rate and pressure, are fixed. Subsequently the thermal plasma is irradiated directly to the polymer specimen.

In this experiment, the input power to the ICTP was set to $8.5 \mathrm{~kW}$ and the Ar sheath gas flow rate was 30 slpm. The Ar gas was used because Ar ICTP is easily established. Moreover, it is chemically stable gas so we can investigate thermal interaction between polymer and thermal plasma. The pressure in the chamber was regulated to around $1.0 \mathrm{~atm}$. During thermal plasma irradiation, the polymer specimen surface was observed using a high-speed video camera. The frame rate of the high-speed video camera observation was set to 1000 frames per second.

\subsection{Spallation occurrence by Ar-ICTP irradiation on PA6 and PA66}

Figure 3 shows the high-speed video camera observation result of Ar-ICTP irradiation of PTFE, PE, POM, PMMA, PA6, PA66, and PF specimens. The thermal plasma is 
irradiated to the specimen from above in this figure. The thermal plasma irradiation to the polymer specimen causes strong ablation of the specimen. As presented in this figure, the radiation from the ablation vapour cloud is clearly visible over the specimen surface. The radiation from the ablated vapour results from the excited molecules and atoms in the ablated vapour irradiated by thermal plasma. The main colour of the radiation is blue, which can originate from $\mathrm{C}_{2}$ Swan band system at wavelengths around 450-570 nm, as found in our previous work [29]. As each picture shows, all the polymers eject more or less ablation vapour. However, results also show that PA6 and PA66 eject not only ablation vapour but also particles above the ablation vapour. These ejected particles are called 'spallation particles'. A spallation particle can be a small piece of the polymer.

If the spallation phenomenon is applied to arc quenching, then spallation particles might penetrate the arc discharge core deeply because of the mass inertia. Then they will be ablated there to decrease the arc temperature effectively. Therefore, spallation particles can be used for effective arc quenching.

\section{Influence of water absorption in PA6 and PA66 on the occurrence of spallation phenomena}

\subsection{Features of PA6 and PA66}

As the preceding section explained, among polymer materials of several kinds, only PA6 and PA66 materials can eject spallation particles during thermal plasma irradiation. Here, some features of PA6 and PA66 are described for consideration of the essence of spallation occurrence.

Polymers PA6 and PA66 are classified as polyamide materials. Polyamide materials are widely used in various applications such as food wrap films, fiber products, some parts of automobiles as well as electrical insulation and ablation parts in low-voltage circuit breakers. Among polyamide materials, polyamide-6 (PA6) and polyamide-66 (PA66) are generally categorized as engineering plastics. Both have high mechanical strength and high chemical resistance. Figure 4 presents the structural formulas of PA6 and PA66. Actually, PA6 has the chemical formula of $\left(-\mathrm{C}_{6} \mathrm{H}_{11} \mathrm{ON}-\right)_{n}$, whereas PA66 has $\left(-\mathrm{C}_{12} \mathrm{H}_{22} \mathrm{O}_{2} \mathrm{~N}_{2}\right)_{n}$. They have mutually similar mechanical, physical, and chemical characteristics. However, PA66 has slightly higher chemical resistance and mechanical strength than the PA6.

Polyamide materials including PA6 and PA66 have amide bonds (-CONH-) in their polymer structures. Polyamide molecules are therefore strongly bonded to each other through amide bonds. High chemical resistance and high mechanical strength of them are due to such amide bonds. In addition, amide bonds cause polyamide materials to have high hydrophilia.

Figure 5 presents schematics showing hydrogen bonds in polyamide materials. Figure 5(a) depicts the normal state of polyamide structure. In the normal state, 
some amide groups have hydrogen bonds with other amide groups. The mechanical strength of polyamide originates from these amide bonds. In addition, amide bonds can have hydrogen bonds through $-\mathrm{C}=\mathrm{O}(\delta-)$ - with water $\left(\mathrm{H}_{2} \mathrm{O}\right)$ because $\mathrm{H}_{2} \mathrm{O}$ has an electric dipole. Figure 5(b) presents an example of the connection occurring with $\mathrm{H}_{2} \mathrm{O}$ molecule in polyamide. The hydrogen atom in amide group has a positive charge. It attracts oxygen atoms of water molecules electrostatically when there are water molecules. Similarly, the hydrogen atom in $\mathrm{H}_{2} \mathrm{O}$ is electrostatically attracted by oxygen atoms of the amide group in polyamide. As a result, the polyamide material has a high hydrophilic property. We inferred that this hydrophilia of polyamide material is related to the occurrence of spallation phenomena.

\subsection{Water absorption test into PA6 and PA66}

First, we confirm the water absorption ability of PA6 and PA66 specimens by soaking a polyamide specimen in water. The specimen with a shape shown in figure 2 is used for water absorption tests. It is also used in thermal plasma irradiation experiments as described in a later section. Other kinds of polymer material specimens such as PTFE, PE, POM, and PMMA were also prepared with the same shape for comparison. The mass of a PA6 specimen was measured as $0.95 \mathrm{~g}$. That of PA66 was $1.0 \mathrm{~g}$. First, PA6 specimens were soaked in pure water for $3 \mathrm{hr}$ at different temperatures: cool temperature $(283 \mathrm{~K})$, room temperature $(295 \mathrm{~K})$, and boiling temperature $(373 \mathrm{~K})$.

Figure 6 presents results of the water absorption ratio for PA6 for different temperatures of $283 \mathrm{~K}, 295 \mathrm{~K}$, and $373 \mathrm{~K}$. Here, the water absorption ratio was defined as shown below.

$$
R_{\text {water }}=\frac{\left(M_{\text {after }}-M_{\text {before }}\right)}{M_{\text {before }}} \times 100[\mathrm{wt} \%]
$$

Therein, $M_{\text {after }}$ is the mass after $3 \mathrm{hr}$ soaking; also $M_{\text {before }}$ is the mass before soaking. The water absorption ratio of PA6 soaked in boiling water $(373 \mathrm{~K})$ was estimated as $4.6 \mathrm{wt} \%$, which is the highest value in these three conditions. Results show that the water absorption ratio of PA6 depends strongly on temperature. This might be true because the lattice distance of PA6 increases with temperature. Then more water is absorbed.

For comparison, figure 7 presents the water absorption ratio of the above polymers of six kinds in boiling water $(373 \mathrm{~K})$ for $3 \mathrm{hr}$. As this figure shows, PA6 has the highest water absorption ratio of $4.6 \mathrm{wt} \%$. The second highest ratio is that of PA66 as $2.6 \mathrm{wt} \%$. However, PTFE and PE materials have extremely lower water absorption ratios because these materials have no dipole in polymer molecules.

Figure 8 presents the water absorption ratio of PA6 and PA66 soaked in boiling water as a function of soaking time. After $40 \mathrm{hr}$ soaking, the water absorption rate of PA6 is 10wt\%; that of PA6 is 6.3wt\%. Actually, PA6 seems to have greater water retention capacity than PA66 has. According to this figure, one can control water absorption ratio of PA6 and PA66 to some degree after soaking. 
The obtained results in this section provide useful information to consideration of the essence of spallation occurrence. Polyamide materials PA6 and PA66 can retain more waters than other kinds of polymer materials treated in this work. Moreover, water retention amount in PA6 and PA66 can be controlled by soaking time and water temperature. The following section will describe the effect of water absorption to PA6 and PA66 on occurrence of spallation during ICTP irradiation.

\subsection{Experimental conditions for Ar-ICTP irradiation on water absorbed PA66 and PA6}

The Ar ICTP irradiation test was conducted for polyamide specimens before and after water absorption. The same experimental setup and the shape of the specimen for ICTP irradiation were used, respectively, as those shown in figures 1 and 2 . The input power to ICTP was set to $9.8 \mathrm{~kW}$. The thermal plasma irradiation time duration was $20 \mathrm{~s}$. The chamber pressure was regulated at $1.0 \mathrm{~atm}$. We did high-speed video camera observations and ablation mass measurements. The frame rate of the high-speed video camera was set to 1000 fps.

We prepared dry PA6 and PA66 specimens, which were placed in a desiccator with silica gel for dry specimens. In addition to these, PA6 and PA66 specimens having soaked in water at room temperature for $10 \mathrm{hr}$ after $5 \mathrm{hr}$ boiling were used for experimentation. This soaking involves the PA6 specimen with $6.8 \mathrm{wt} \%$ water absorption and the PA66 specimen with $3.9 \mathrm{wt} \%$ water absorption.

\subsection{High-speed video camera observation of spallation occurrence from PA6 / PA66 irradiated by Ar ICTP}

Figure 9 shows high-speed video images of PA6 and PA66 specimens irradiated by Ar ICTP. In each case, the ICTP is generated at input power of $9.8 \mathrm{~kW}$ and Ar sheath gas of $50 \mathrm{slpm}$. The thermal plasma is irradiated from the top side in these figures. The observation direction is perpendicular to the plasma flow direction. Radiation from Ar thermal plasmas is only slightly detectable because the radiation from Ar spectral line is lower than that from ablated vapour. Every panel (a)-(d) shown here is a superimposed image of over 100 images captured in $0.1 \mathrm{~s}$, from $0.9 \mathrm{~s}$ after the beginning of irradiation up through $1.0 \mathrm{~s}$.

Figure 9(a) shows the case of Ar ICTP irradiation on dry PA6 specimen. Light emission from ablation vapour is apparent around the specimen. The main colour of the light is blue, which originated by $\mathrm{C}_{2}$ Swan system. From the $\mathrm{C}_{2}$ spectra, we estimated the vibrational and rotational temperatures of $\mathrm{C}_{2}$ in ablated vapor as about $4000 \mathrm{~K}$, while the Ar excitation temperature was estiamted as about $8000 \mathrm{~K}$ in the Ar ICTP by two-line method of Ar atomic lines [28]. Faint purple light is also apparent in some parts of the picture. The colour purple comes from the intensity of CN violet spectra at wavelengths around $350-400 \mathrm{~nm}$. In this case of PA6 without water absorption, spallation phenomena only slightly occur. 
Figure 9(b) depicts the case of Ar ICTP irradiation on PA6 with 6.8wt\% water absorption. The image in figure $9(\mathrm{~b})$ is clearly different from the previous picture of dry PA6 in figure 9(a). Small particles were ejected from the specimen surface They were ablated above the ablation vapour layer. These particles are spallation particles. This result demonstrates that water absorption promotes spallation particle ejection from the PA6 specimen. Ejected spallation particles are ablated in the irradiated thermal plasma. They emit blue light originating from $\mathrm{C}_{2}$ molecular spectra during their flight. Therefore, spallation particles can penetrate deeply into high-temperature thermal plasma. Then they can be ablated to suppress the thermal plasma temperature. The number of spallation particles ejected high above the ablation gas layer reaches 24 from figure $9(\mathrm{~b})$.

Figure $9(\mathrm{c})$ portrays the case of dry PA66. The ablated aspect of PA66 in this figure is similar to the case of dry PA6 shown in figure 9(a), although the purple colour strength of PA66 ablation vapour is slightly higher than that of PA6. In this case, no spallation particle was ejected from the dry PA66 specimen. Figure 9(d) depicts the result of PA66 with 3.9wt\% water absorption. Although the water absorption ratio of PA66 in this figure differs from that of the PA6 specimen used in figure 9(b) (6.8wt\%), spallation particles ejected from the specimen are clearly detectable. The spallation particles ejected high above the ablation gas layer were 17 .

These high-speed video camera observation results above confirmed that spallation phenomena result from water absorption in the polyamide materials of PA6 and PA66. The mechanism of spallation occurrence has not been explained completely yet, but we infer the following description.

(i) The heat flux from thermal plasma plasticizes the surface of the polyamide bulk.

(ii) Water molecules are desorbed. Then they condense into droplets.

(iii) The water droplets are heated and evaporated to increase the internal pressure under the polymer surface.

(iv) When the internal pressure increases to withstand pressure of polyamide mechanically, the parts of polyamide are broken up. That effect causes particle ejection to thermal plasmas.

\subsection{Ablation mass of PA6 / PA66 irradiated by Ar ICTP for $20 \mathrm{~s}$}

Figure 10 presents the ablated mass of polyamide specimens that had been irradiated for $20 \mathrm{~s}$ by Ar ICTP. The ablation mass was estimated from the different measurements conducted before and after irradiation of Ar ICTP. The ablated mass of dry PA6 without water absorption is about $60-70 \mathrm{mg}$, which is approximately equal to that of dry PA66 without water absorption. However, both the water-absorbed PA6 specimen and waterabsorbed PA66 specimen were ablated about $100 \mathrm{mg}$, which is about 1.5 times higher than that of dry PA6 and PA66 specimens. It is noteworthy that the mass of absorbed water is only several percent of the specimen mass. The facts presented above imply that water absorption to polyamide specimens increases the ablation mass. This increase 
in ablation mass by water absorption might result from the mass loss from spallation particle ejection.

\section{5. $\mathrm{Ar}+\mathrm{N}_{2} / \mathrm{O}_{2}$ ICTP irradiation on PA66 with water absorption}

\subsection{Experimental conditions for $\mathrm{Ar}+\mathrm{N}_{2} / \mathrm{O}_{2}$ ICTP irradiation on water absorbed} PA66

This section presents an examination of the influence of chemical reactions in thermal plasmas irradiated to the PA66 specimen on the occurrence of spallation phenomena from water absorbed PA66. The PA66 specimens used in this work had 3wt\% water absorption. Gases $\mathrm{N}_{2}$ and $\mathrm{O}_{2}$ and their mixture gas were supplied to Ar ICTP irradiated to the water absorbed PA66 specimen. These gases and gas mixtures were selected for use in this study because they are contents of air. In addition, we have strived to study the influence of chemical reactions in air thermal plasma on the spallation occurrence, for use in arc quenching in a circuit breaker. In this work, six thermal plasma conditions were tested. The first one is the case of Ar ICTP irradiation, which is designated as Cond. $A=$ Condition $A$ in Table 2. The second one is $\mathrm{N}_{2}$ inclusion case to Ar ICTP, designated as Condition $B$. The cases of $\mathrm{N}_{2}$ and $\mathrm{O}_{2}$ inclusion to Ar ICTP are Cond. $C^{-}$, Cond. $C$ and Cond. $C^{+}$. The difference between $C^{-}, C$ and $C^{+}$is the admixture ratio of $\mathrm{N}_{2} / \mathrm{O}_{2}$. The last case is $\mathrm{O}_{2}$ inclusion to Ar ICTP, designated as Cond. D.

We supposed to use the spallation particles, for example, to affect the air arc plasma in a low-voltage circuit breaker as one application. Therefore, the above 6 conditions were set in the experiments. ConditionA corresponds to influence only from the heat. Condition $B$ is to confirm influence of presence of nitrogen related particles such as $\mathrm{N}_{2}, \mathrm{~N}_{2}^{+}, \mathrm{N}$ and $\mathrm{N}^{+}$on the spallation occurrence from chemical reactions on the the polyamide surface. Nitrogen is a main gas constituent of air. ConditionD is similarly to confirm the influence of $\mathrm{O}$ related particles on the spallation occurrence from chemical reactions on the the polyamide surface.. Oxygen is the second gas constituent of air. Conditions $C^{-}, C, C^{+}$are the ones to study effect of nitrogen oxides such as $\mathrm{NO}, \mathrm{N}_{2} \mathrm{O}$, $\mathrm{NO}^{+}$etc on the spallation occurrence.

For each of the six conditions, the heat flux from the thermal plasma to the specimen is expected to be almost identical because different heat flux might cause different interaction between the thermal plasma and polymer specimen. To ascertain the same heat flux condition for different gas mixtures of thermal plasma, we set the different input power to different gas mixture thermal plasma in the following manner. Figure 11 depicts the surface temperature dependence of a $\mathrm{TiO}_{2}$ specimen with a diameter of 15 $\mathrm{mm}$ and a thickness of $5 \mathrm{~mm}$ (instead of bulk polymer) on the input power to the thermal plasma given different gas conditions. The surface temperature of $\mathrm{TiO}_{2}$ specimen on the water-cooled specimen holder was measured using a radiation thermometer. The $\mathrm{TiO}_{2}$ specimen was used to estimate the heat flux from the surface temperature measurement because $\mathrm{TiO}_{2}$ is extremely stable for thermal plasmas and chemical species in thermal 
plasmas. This figure shows that the surface temperature of the $\mathrm{TiO}_{2}$ specimen increases concomitantly with increasing input power to the thermal plasma, and that it depends markedly on the gas mixture condition. Using this figure, the input power for the same heat flux condition for different gas mixtures was determined from the same surface temperature $800{ }^{\circ} \mathrm{C}$ of a $\mathrm{TiO}_{2}$ specimen. This method of inference provides the same heat flux conditions. In this case, the irradiated heat flux was estimated as around $500 \mathrm{~kW} / \mathrm{m}^{2}$ from the aid of a numerical simulation of induction thermal plasma with a specimen. The determined values of input power for different gas mixture conditions were added to Table 2.

In the irradiation experiment, high-speed video camera observations and ablation mass measurements were conducted. From the high-speed video camera observation, spallation particles were counted from the PA66 specimens.

\subsection{High-speed video camera observation on spallation occurrence from PA66 with water absorption irradiated by $\mathrm{Ar}+\mathrm{N}_{2} / \mathrm{O}_{2} \mathrm{ICTP}$}

5.2.1. Ablation aspect and spallation occurrence Figure 12 presents four images captured using a high-speed video camera during $\mathrm{Ar}+\mathrm{N}_{2} / \mathrm{O}_{2}$ ICTP irradiation on water absorbed PA66. Irradiation of the Ar ICTP with different gas mixtures provides a quite different aspect of PA66 ablation. For 100\% Ar ICTP irradiation, ablated vapour from PA66 emits white-bluish light, which is mainly attributed to strong spectral intensity from $\mathrm{C}_{2}$ Swan system at wavelengths of $450-570 \mathrm{~nm}$. The $97 \%$ Ar ICTP with $3 \% \mathrm{~N}_{2}$ produces ablated vapour with similar colour but also with purple around the PA66 surface. The colour purple comes from the high intensity of $\mathrm{CN}$ violet spectra at wavelengths of 350-400 nm. Inclusion of $\mathrm{O}_{2}$ in the Ar ICTP involves orange colour in ablated vapour, which might arise from the continuous spectra by black-body radiation according to spectroscopic measurements [29, 28]. This seems attributable to the combustion reaction of graphite particles in ablated vapour. In every case, the PA66 specimens eject spallation particles.

5.2.2. Influence of $\mathrm{N}_{2}$ or $\mathrm{O}_{2}$ inclusion on the number of spallation occurrence Figure 13 presents four images produced by accumulation of 100 consecutive video images from $0.9 \mathrm{~s}$ to $1.0 \mathrm{~s}$ after ICTP irradiation in different conditions. As the figure shows, both $\mathrm{N}_{2}$ and $\mathrm{O}_{2}$ can promote spallation occurrence. Especially, inclusion of $\mathrm{N}_{2}$ and $\mathrm{O}_{2}$ seems to influence the ablation and spallation occurrence. Using sequence images taken by the high-speed video camera, the spallation particles were counted. Only the particles jumping up to the top of the ablation vapour layer were counted.

Figure 14 shows the instantaneous and cumulative numbers of spallation particles versus time from the beginning of ICTP irradiation. Each panel corresponds to the results counted from each panel shown in figures 12 and 13 . The left vertical axis shows the instantaneous number of spallation particles, which is indicated by black bars. The right vertical axis shows the cumulative number of spallation particles, which 
is presented by curves. The 'instantaneous number' treated here is the number of spallation particles ejected at each time. In the case of $100 \% \mathrm{Ar}$, the first spallation particle was ejected at $300 \mathrm{~ms}$ after the beginning of ICTP irradiation. Spallation particles were ejected thereafter. During 1000 ms 100\% Ar ICTP irradiation, 75 particles were ejected in all. For $97 \% \mathrm{Ar}+3 \% \mathrm{~N}_{2}$, the first ejected spallation particle was detected at $300 \mathrm{~ms} ; 83$ particles were ejected in $1000 \mathrm{~ms}$. The $97 \% \mathrm{Ar}+1.5 \% \mathrm{~N}_{2}+1.5 \% \mathrm{O}_{2}$ ICTP irradiation involves the first ejection of a spallation particle at $300 \mathrm{~ms}$. It has 113 particles ejection in all. Similarly, the $97 \% \mathrm{Ar}+3 \% \mathrm{O}_{2}$ ICTP irradiation causes the first spallation particle ejection at $220 \mathrm{~ms}$; actually, 116 particles were ejected. These results demonstrate that inclusion of $\mathrm{O}_{2}$ promotes spallation occurrence.

The total cumulative quantities of spallation particles ejected in $1.0 \mathrm{~s}$ for each ICTP condition are presented in figure 15. Each condition has three data. The average of these three experiments is shown there. The figure shows results of six conditions for comparison, including extra conditions $C o n d . C^{-}$and $C o n d . C^{+}$. One might recall that Cond. $A$ is the case of $100 \%$ Ar, Cond. $B$ is for $\mathrm{N}_{2}$ inclusion, the three series of Cond. $C, C^{+}, C^{-}$are the cases of both $\mathrm{N}_{2}$ and $\mathrm{O}_{2}$ inclusion with change of the mixture ratio. Also, Cond. $D$ is the case of $\mathrm{O}_{2}$ inclusion. As this figure shows, pure Ar ICTP engendered 62 spallation particles, which is the lowest value among the six cases. With $\mathrm{N}_{2}$ gas inclusion to Ar ICTP, the number of spallation particles increased to 74. Inclusion of both $\mathrm{N}_{2}$ and $\mathrm{O}_{2}$ mixture further increases the number of spallation particles detected. In the $\mathrm{N}_{2}$ and $\mathrm{O}_{2}$ mixture cases, a higher $\mathrm{O}_{2}$ inclusion ratio tends to enhance the occurrence of spallation. As the $\mathrm{O}_{2}$ mixture ratio rises, the number of spallation particles increases to 120 . Only $\mathrm{O}_{2}$ inclusion maintains a high value of the spallation occurrence over 100 . This result implies the importance of chemical reactions with oxygen on the polymer surface for spallation occurrence.

5.2.3. Ablation of a spallation particle flying in thermal plasma High-speed video camera observations revealed that the spallation particles flying in thermal plasmas was ablated during their flights. Figure 16 depicts the course of ablation of a spallation particle ejected during $97 \% \mathrm{Ar}+1.5 \% \mathrm{~N}_{2}+1.5 \% \mathrm{O}_{2}$ ICTP irradiation. From this figure, a particle was ejected at the time $2.478 \mathrm{~s}$ after the beginning of ICTP irradiation. The particle reached the top of the jump at the time of $2.482 \mathrm{~s}$, which corresponds to $4 \mathrm{~ms}$ after the beginning of the ejection. The particle was ablated during their falling down flight. The particle was lost by ablation to the time $2.485 \mathrm{~s}$, corresponding to $7 \mathrm{~ms}$ after the ejection. As shown there, most spallation particles were ablated completely in less than $10 \mathrm{~ms}$ for all cases. Results show that the time required for ablation is sufficiently short for arc quenching. 
5.3. Ablation mass of $3 w t \%$ water absorbed PA66 irradiated by Ar $+\mathrm{N}_{2} / \mathrm{O}_{2}$ ICTP for $20 \mathrm{~s}$.

The ablation mass of PA66 irradiated by $\mathrm{Ar}+\mathrm{N}_{2} / \mathrm{O}_{2}$ ICTP for $20 \mathrm{~s}$ is described in this section. Figure 17 presents the ablation mass of the water absorbed PA66 specimen irradiated by $\mathrm{Ar}+\mathrm{N}_{2} / \mathrm{O}_{2}$ ICTP for $20 \mathrm{~s}$. As described previously, the ablation mass was calculated only as a mass difference between measurements taken before and after ICTP irradiation. The bar in this figure shows the average value obtained from three experiments conducted under the same conditions. All experiments used water-absorbed PA66 specimens, which promotes spallation occurrence.

As this figure shows, the ablation mass is 100-150 mg for all conditions. Comparison of results shown in figures 15 and 17, shows that the ablation mass seems to depend roughly on the number of spallation particles. Increasing the sum of spallation particles elevates the ablation mass slightly, which implies that the spallation particles naturally contribute to the mass loss of the specimen.

The results of $\mathrm{Ar}+\mathrm{N}_{2} / \mathrm{O}_{2}$ ICTP irradiation experiment confirmed that both $\mathrm{N}_{2}$ and $\mathrm{O}_{2}$ can promote the occurrence of spallation phenomena from water absorbed polyamide. Thus, the air is expected to promote the occurrence of spallation because air contains both $\mathrm{N}_{2}$ and $\mathrm{O}_{2}$ in moderate mixture ratio. Therefore, we expect spallation phenomena to promote arc quenching effectively, because many low voltage circuit breakers such as mold case circuit breakers (MCCBs) work in open air.

\section{Numerical estimation on cooling effects of spallation particles on high-temperature air.}

\subsection{Assumptions}

This section presents a description of numerical estimation on the cooling effects of spallation particles on high-temperature air. As described in the preceding sections, spallation particles are ejected from the PA66 surface to the thermal plasma, where they are ablated. That ablation can involve cooling of thermal plasma because of its latent heat for thermal decomposition and mixing of ablated vapour. The ablated vapour has some polyatomic molecular species. The mixture of these molecules has high effective specific heat capacity. Also, they are decomposed and consume the energy from the thermal plasma. We suppose to adopt spallation particles ejection to the arc plasma when the polyamide material is used to a circuit breaker. Arc-extinguishing chamber in a circuit breaker is much smaller than the ICTP chamber we used in preceding sections. Therefore, fundamental estimation is needed to clarify the arc-quenching ability of spallation particles. However, it is not easy to distinguish the cooling effects into ablation vapour effects and spallation particles effects by the experiments because they occur simultaneously. Therefore, we do numerical esimation of the cooling effect of a single spallation particle or more spallation particles on air thermal plasma.

Here, we presume a high-temperature air with a volume of $10 \mathrm{~mL}\left(=10 \times 10^{-6} \mathrm{~m}^{3}\right)$ 
at a certain initial temperature $T_{\text {air }}$ at atmospheric pressure $101325 \mathrm{~Pa}$. The volume of $10 \mathrm{~mL}$ is one typical volume of an arc in a small moulded case circuit breaker. It is assumed that in this high-temperature air PA66 sphere particles with a radius of 100 $\mu \mathrm{m}$ and a mass of $4.77 \mu \mathrm{g}$ at $300 \mathrm{~K}$ would be injected. They would be evaporated completely because of high-temperature air involving a decrease in the air temperature, and then they would be PA66 vapour including polyatomic molecules of several kinds in high-temperature air at fixed atmospheric pressure. After mixing PA66 vapour with high-temperature air uniformly, the mixture would have to reach final temperature $T_{\mathrm{f}}$ and final volume $V_{\mathrm{f}}$ at fixed atmospheric pressure. We calculate $T_{\mathrm{f}}$ for those conditions in the following subsections.

The initial temperature of the high-temperature air $T_{\text {air }}$ was set to 5000,7500 , 10000,12500 , or $15000 \mathrm{~K}$. The number of injected spallation particles is assumed to be $1,5,10,30$, or 50 .

\subsection{Thermodynamic properties for calculating cooling effects}

6.2.1. Equilibrium composition, mass density and enthalpy of high-temperature air First, the equilibrium composition of high-temperature air was calculated by minimization of the Gibb's free energy of the system [12, 25, 30, 31]. Gibb's total free energy $G$ can be written as

$$
\begin{aligned}
& G=\sum_{i=1}^{N} n_{i}\left(\mu_{i}^{0}+R T \ln \left(\frac{n_{i}}{N}\right)+R T \ln \left(\frac{P}{P_{0}}\right)\right) \\
& \mu_{i}^{0}=-R T \ln \left(Z_{i}^{\mathrm{tr}}\right)-R T \ln \left(Z_{i}^{\mathrm{int}}\right)+\Delta H_{\mathrm{f} i}
\end{aligned}
$$

where $N$ stands for the total number density of particles, $n_{i}$ is number density of the $i^{\text {th }}$ particle, $T$ is temperature $(\mathrm{K}), R$ is gas constant $(\mathrm{J} / \mathrm{mol} / \mathrm{K}), Z_{i}^{\text {tr }}$ and $Z_{i}^{\text {int }}$ are partition function of translational motion and internal state, respectively, $\Delta H_{\mathrm{f} i}$ is standard enthalpy of formation $(\mathrm{J} / \mathrm{mol}), P$ is the pressure, $P_{0}$ is the reference pressure. In this work, $P=P_{0}=101325 \mathrm{~Pa}$ was set.

In this situation, we assumed that composition of high-temperature air can be described as $78 \% \mathrm{~N}_{2}+21 \% \mathrm{O}_{2}+1 \%$ Ar. Figure 18 presents the equilibrium composition of air at 101,325 Pa. The vertical axis shows the number density of the constituent species. The horizontal axis shows the gas temperature. At room temperature 300 $\mathrm{K}$, the main components of air are $\mathrm{N}_{2}, \mathrm{O}_{2}$, and Ar. As the gas temperature rises, decomposition or association reactions of molecules can produce polyatomic molecules. At temperatures of $500 \mathrm{~K}$ to $1000 \mathrm{~K}$, NO and $\mathrm{N}_{2} \mathrm{O}$ molecules generated by decomposition and association are apparent. At temperatures from $1000 \mathrm{~K}$ to $10000 \mathrm{~K}$, atomic species $\mathrm{O}$ and $\mathrm{N}$ appear. In addition, a small number density of $\mathrm{O}_{3}$ and $\mathrm{N}_{3}$ is apparent. At temperatures higher than $10000 \mathrm{~K}$, most species become mono-atomic ions. The number density of electrons rises.

Using this equilibrium composition of air, one can calculate the mass density and

the enthalpy of air at a certain temperature. Mass density of air $\rho$, which is the total 
mass of constituent species can be described as the following equation.

$$
\rho=\sum_{i} m_{i} n_{i}
$$

Therein, $m_{i}$ stands for the mass of species $i$, and $n_{i}$ denotes the number density of species $i$. Enthalpy $h$ is calculable with the internal partition function $Z_{i}^{\text {int }}$ and the standard enthalpy of formation $\Delta H_{\mathrm{f} i}$ :

$$
h=\frac{1}{\rho} \sum_{i}\left(\frac{5}{2} k T+k T^{2} \frac{\partial}{\partial T}\left(\ln Z_{i}^{\text {int }}\right)+\Delta H_{\mathrm{f} i}\right) n_{i}
$$

Figures 19 and 20 respectively show the temperature dependence of the mass density $\rho$ and the enthalpy $h$ of air. Because we have assumed that the initial volume of air is $10 \mathrm{~mL}\left(=10 \times 10^{-6} \mathrm{~m}^{3}\right)$, we obtain the mass of the air from the mass density. At a temperature of $5000 \mathrm{~K}$, the mass of $10 \mathrm{~mL}$ air is $583 \mu \mathrm{g}, 174 \mu \mathrm{g}$ for $10000 \mathrm{~K}$, and 78 $\mu \mathrm{g}$ for $15000 \mathrm{~K}$. Results show that the mass of air decreases as the temperature rises at a fixed pressure. However, the enthalpy increases with a temperature rise. At a temperature $5000 \mathrm{~K}$, the enthalpy of air is $10.2 \mathrm{~kJ} / \mathrm{g}$. It is $114 \mathrm{~kJ} / \mathrm{g}$ for $15,000 \mathrm{~K}$. By multiplying the initial mass and the enthalpy, one obtains the internal thermal energy of air within $10 \mathrm{~mL}$ volume. Table 3 expresses the temperature and the internal thermal energy of $10 \mathrm{~mL}$ air. At $5000 \mathrm{~K}$, the internal thermal energy of $10 \mathrm{~mL}$ air is $59.5 \mathrm{~J}$. For temperatures higher than $7500 \mathrm{~K}$, the internal thermal energy reaches 80-90 J.

6.2.2. Variation in composition, internal thermal energy of high-temperature air with inclusion of PA66 spallation particles We assumed PA66 sphere particles with a radius of $100 \mu \mathrm{m}$ and a mass of $4.77 \mu \mathrm{g}$ at $300 \mathrm{~K}$. The PA66 particles would be included in high-temperature air. The particles were decomposed to produce PA66 vapour including polyatomic molecules, which are mixed with air. To consider the dominant species in air-PA66 vapour at a specified temperature, the equilibrium composition of airPA66 vapour was calculated by minimization of the Gibb's free energy. The air-PA66 vapour admixture ratio depends on the initial temperature $T_{\text {air }}$ and the number of PA66 spallation particles. For example, for air with an initial temperature of $5000 \mathrm{~K}$ and 1 spallation particle injection, the mass ratio of the air to PA66 is $583: 4.77$. The mass ratio is expected to take a value of $174: 47.7$ with 10 particles injection if the initial temperature of the air were $10,000 \mathrm{~K}$.

Figure 21 depicts the equilibrium composition of air-PA66 vapour mixture generated by 1 particle injection into the air of the initial temperature $10000 \mathrm{~K}$ at atmospheric pressure. In this case, the mass ratio of air to PA66 is $174: 4.77$. The horizontal axis shows the gas temperature. The vertical axis shows the number density of the constituent species. The composition in figure 21 is greatly complicated compared to the composition presented in figure 18. This result derives from inclusion of $\mathrm{C}$ atoms and $\mathrm{H}$ atoms from PA66 vapour. A PA66 $\left(\mathrm{C}_{12} \mathrm{H}_{22} \mathrm{O}_{2} \mathrm{~N}_{2}\right)$ spallation particle can provide $\mathrm{C}$ and $\mathrm{H}$ atoms to produce numerous and diverse species. In temperatures of $500 \mathrm{~K}$ to $1000 \mathrm{~K}$, polyatomic or diatomic molecules are dominant. At temperatures from $1000 \mathrm{~K}$ 
to $10000 \mathrm{~K}$, the mono-atom species number density of increases. A further increase in temperature to more than $10000 \mathrm{~K}$ makes the dominant species ions. In this way, PA66 particle inclusion to air causes considerable changes in the equilibrium composition of the air.

Using the calculated equilibrium compositions, the enthalpy of air-PA66 vapour mixtures is derived from equation (5). Figure 22 presents the temperature dependence of enthalpy of air-PA66 vapour mixtures with different admixture ratios of PA66. The admixture ratios here correspond to those calculated for $0,1,5,10,30$, and 50 PA66 particles injected into $10 \mathrm{~mL}$ volume of air with an initial temperature of $10,000 \mathrm{~K}$ at atmospheric pressure, as described previously. As this figure shows, one or more particles injection rises the enthalpy of the vapour mixture at a fixed temperature. As increasing admixture ratio of PA66, which is shown with increasing the number of PA66 particles in this figure, the enthalpy of air-PA66 vapour is elevated at fixed temperatures. This elevation is attributed to the fact that air-PA66 vapour has complex polyatomic species carrying internal energy.

\subsection{Calculation procedure for cooling effect of PA66 particles in high-temperature air}

Thermal decomposition of PA66 particles and PA66 vapour mixing with dissociation reactions of polyatomic species lead to a temperature decrease of air from an initial temperature. After thermal decomposition and mixing, the mixture from $10 \mathrm{~mL}$ hightemperature air and PA66 particles has a final temperature $T_{\mathrm{f}}$. This final temperature $T_{\mathrm{f}}$ is obtainable by solving the following energy conservation equation:

$$
m_{\text {air }} h_{\text {air }}\left(T_{\text {air }}\right)=h_{\mathrm{PA} 66-\text { air }}\left(T_{\mathrm{f}}\right) \times\left(m_{\text {air }}+m_{\mathrm{PA} 66}\right)+Q_{\mathrm{e}} \times m_{\mathrm{PA} 66}
$$

where $m_{\text {air }}$ signifies the mass of the high-temperature air, $m_{\mathrm{PA} 66}$ denotes the mass of PA66 particles, $h_{\text {air }}\left(T_{\text {air }}\right)$ represents the enthalpy of the air at the initial temperature $T_{\text {air }}$, and $h_{\mathrm{PA} 66-\text { air }}\left(T_{\mathrm{f}}\right)$ stands for the enthalpy of the gas mixture of PA66-air at a final temperature $T_{\mathrm{f}}$. Also, $Q_{\mathrm{e}}$ is the latent heat of PA66 from $300 \mathrm{~K}$ to the thermal decomposition temperature at atmospheric pressure. The value of $Q_{\mathrm{e}}$ is about $2.508 \mathrm{~J}$ per particle. Equation 6 can be expressed as

$$
h_{\mathrm{PA} 66-\mathrm{air}}\left(T_{\mathrm{f}}\right)=\frac{m_{\mathrm{air}} h_{\mathrm{air}}\left(T_{\mathrm{air}}\right)-Q_{\mathrm{e}} \times m_{\mathrm{PA} 66}}{m_{\mathrm{air}}+m_{\mathrm{PA} 66}}
$$

We can estimate the final temperature $T_{\mathrm{f}}$ satisfying the above equation (7). For $h_{\mathrm{PA} 66-\text { air }}$, we can use data in figure 22.

\subsection{Calculation results of spallation particle cooling effects}

Table 4 quantifies the final temperatures $T_{\mathrm{f}}$ for each initial temperature $T_{\text {air }}$ and number of spallation particles. These are also presented in figure 23. For the cases of initial air temperature $T_{\text {air }}=10,000 \mathrm{~K}$, a single PA66 particle can drop the temperature to $9300 \mathrm{~K}$. This result demonstrates that one PA66 particle has a $700 \mathrm{~K}$ cooling effect. This cooling effect increases to more than $3000 \mathrm{~K}$ for 10 and more particles. This is a large cooling 
effect for arc quenching attributable solely to 10 PA66 particles. The primary factor underlying the cooling effects is the energy consumption from dissociation of molecules contained in PA66 ablation vapour. At high initial temperatures, where the mass of initial air is low because of its low density, the ablation of spallation particles results in greater cooling effects for air.

In the $\mathrm{Ar}+\mathrm{N}_{2} / \mathrm{O}_{2}$ ICTP irradiation experiment described above, more than 30 spallation particles were ejected in $0.1 \mathrm{~s}$. Considering the arc plasma ignited in a circuit breaker, the heat flux of the arc will be much higher than that of ICTPs. In addition, an arc in air contains plenty of $\mathrm{N}_{2}$ and $\mathrm{O}_{2}$, which can promote spallation occurrence. We can expect tens of spallation particles to drop thousands of Kelvin of the air arc temperature compared to no spallation particles if spallation phenomena are applied as a circuit breaker.

\section{Conclusions}

This paper presents a study of the effect of water absorption to polyamide material on the occurrence of spallation phenomena: the particle ejection after breaking off from polymer materials irradiated by high heat flux. The experimentally obtained results demonstrated that polyamide specimens with water absorption ejected spallation particles, whereas polyamide specimens without water absorption ejected them only slightly. These results demonstrate that water absorption can promote spallation phenomena. Furthermore, $\mathrm{N}_{2}$ and $\mathrm{O}_{2}$ inclusions irradiated in thermal plasma enhance spallation phenomena.

Cooling effects of thermal plasmas by spallation PA66 particles were also estimated numerically. This estimation shows that 10 and more PA66 particles inclusion might decrease the air temperature by $3000 \mathrm{~K}$. This temperature drop arises mainly from the energy consumption for dissociation reactions in polyatomic species in air-PA66 ablation vapour. These results suggest that spallation phenomena can be useful to enhance arc quenching in circuit breakers work in air.

We have studied contributing factors on the spallation occurrence from polyamide materials, and a fundamental method of ejection frequency control of spallation particles. Water absorption is the simplest method for spallation occurrence. Furthermore, we are also developing a new other enhancer of spallation phenomena instead of water [32], because it is hard to keep water in polyamide materials for a long time. Nevertheless, we believe that spallation phenomena can be one of the strongly effective applications for arc quenching or temperature control in various arc devices, including circuit breakers. For the acutal use of spallation phenomena for a circuit breaker, it is necessary to conduct further arc quenching tests.

\section{References}

[1] Andre P 1996 Composition and thermodynamic properties of ablated vapours of PMMA, PA6-6, PETP, POM and PE J. Phys. D: Appl. Phys. 29 1963-72 
[2] Andre P 1997 The influence of graphite on the composition and thermodynamic properties of plasma formed in ablated vapour of PMMA, PA6-6, PETP, POM and PE used in circuit-breakers J. Phys. D: Appl. Phys. 30 475-93

[3] E Domejean, P Chévrier, C Fiévet and P Petit 1997 Arc-wall interaction modelling in a low-voltage circuit breaker J. Phys. D: Appl. Phys. 30 2132-42

[4] C Fiévet, M Barrault, P Petit, P Chévrier, C Fleurier and V André 1997 Optical diagnostics and numerical modelling of arc re-strikes in low-voltage circuit breakers J. Phys. D: Appl. Phys. 30 $2991-9$

[5] Uchii T, Shinkai T and Suzuki K 2002 Thermal interruption capability of carbon dioxide in a puffer-type circuit breaker utilizing polymer ablation IEEE/PES Transmission and Distribution Conference and Exhibition 2002 (Yokohama, Japan) 3 1750-4

[6] Swierczynski B, Gonzalez J J, Teulet P, Freton P, and Gleizes A 2004 Advances in low-voltage circuit breaker modelling J. Phys. D: Appl. Phys. 37 595-609

[7] Markutsya S, Rapeaux M and Tsukruk V V 2005 Intensive electric arc interaction with polymer surfaces: Reorganization of surface morphology and microstructure Polymer 46(18) 7028-36

[8] Onchi T, Yanase H, Yamazaki M, Kuroda M, Isozaki M, Sugiyama S, Hata J and Yonemitsu K 2007 Properties of arc initiated between the parallel polymer plates IEEJ Trans. Power and Energy 127(6) 692-8

[9] Nossov V V, Hage B, Jusselin B and Fievet C 2007 Simulation of the thermal radiation effect of an arc on polymer walls in low-voltage circuit breakers Technical Physics 52(5) 651-9

[10] Ma Q, Rong M, Murphy A B, Wu Y, Xu T and Yang F 2008 Simulation and experimental study of arc motion in a low-voltage circuit breaker considering wall ablation IEICE Trans. Electronics E91-C(8) 1240-8

[11] Tanaka Y, Sakuyama T, Yamada D, Uesugi Y, Kanedo S and Okabe S 2008 Effect of polymer ablation on temperature decay of thermal plasmas using induction thermal plasma irradiation technique Proc. 17th Int. Conf. on Gas Discharges and Applications (Cardiff, UK) pp 89-92 paper 89

[12] Tanaka Y, Takeuchi Y, Sakuyama T, Uesugi Y, Kaneko S and Okabe S 2008 Numerical and experimental investigations of thermal interaction between thermal plasma and solid polymer powders using induction thermal plasma technique J. Phys. D: Appl. Phys. 41025203 (15pp)

[13] Vavra Z and Tuma J 2009 A study of electric arc - Polymer materials interaction 18th Symposium on Physics of Switching Arc, FSO 2009; Brno; Czech Republic 300-3

[14] Becerra M, Piva D, Gati G and Dominguez G 2011 Proc. 19th Symposium on Physics of Switching Arc 2011, FSO 2011; Brno; Czech Republic 113-6

[15] Imae T, Kuroki Y, Gaja K, Kaneko E, Hayashida T and Nishi T 2011 Ablation characteristics of the different kinds of polymer insulators Proc. First International Conference on Electric Power Equipment - Switching Technology, ICEPE2011 (Xi'an, China) No. 6123062 598-601

[16] Sakuyama T, Tanaka Y, Uesugi Y, Kaneko S and Okabe S 2012 Plasma-quenching efficiency of ablated vapor of polymer containing nitrogen atoms using inductively coupled thermal plasma technique Electr. Eng. Japan 178 461-8

[17] Jonsson E, Runde M, Dominguez G, Friberg A and Johansson E 2012 Arc quenching performance due to ablation; Comparison between four common polymers Proc. 26th International Conference on Electrical Contacts, ICEC 2012 (Beijing, China) 2012(605) 41-4

[18] Onchi T, Tanaka Y and Uesugi Y 2012 Effect of polymer ablation gas on arc quenching properties around current zero Electr. Eng. Japan 180(3) 32-45

[19] Becerra M and Gati R 2013 Time-resolved ablation of polymers exposed to ac arcs in air Proc. 20th Symposium on Physics of Switching Arc 2013, FSO 2013; Brno; Czech Republic 84-7

[20] Fei Yang, Yi Wu, Mingzhe Rong, Hao Sun, Anthony B Murphy, Zhigang Ren and Chunping Niu 2008 Low-voltage circuit breaker arcs - simulation and measurements J. Phys. D: Appl. Phys. 46273001 (19pp)

[21] Okano Y, Kaneko E and Hayashida T 2013 Study on polymer insulators in air discharge Proc. 
Second International Conference on Electric Power Equipment - Switching Technology, ICEPEST 2013 (Matsue, Japan) 3-a2-P-1 6804388

[22] Becerra M and Friberg A 2014 Arc jets blown by outgassing polymers in air Proc. Int. Conf. on Gas Discharge and their Applications pp 75-78

[23] Choi Y K and Shin J K 2015 Arc Gas-Flow Simulation Algorithm Considering the Effects of Nozzle Ablation in a Self-Blast GCB IEEE Trans. Power Delivery 30(4) 1663-8

[24] Aminlashgari N Becerra M and Hakkarainen M 2016 Characterization of degradation fragments released by arc-induced ablation of polymers in air J. Phys. D: Appl. Phys. 49055502 (9pp)

[25] Tanaka Y, Numada T, Kaneko S and Okabe S 2005 Thermodynamic and transport properties of polymer ablated vapors and influence of their inclusions on Ar induction thermal plasma temperature JSME International Journal, Ser.B 48(3) 417-24

[26] Tanaka Y, Shinsei N, Amitani K, Wada J and Okabe S 2011 Spallation particle ejection from polymer surface irradiated by thermal plasmas IEEE Trans. Plasma Sci. 39(11) 2776-7

[27] Nakagawa T, Nakano T, Tanaka Y, Uesugi Y and Ishijima T 2015 Numerical simulation on dynamics and thermal decomposition of spallation polymer particles flying in polymer ablated arcs Trans.IEEJ 135(11) (7pp)

[28] Tanaka Y, Sakuyama T, Yamada D, Uesugi Y, Kaneko S and Okabe S 2008 Effect of polymer ablation on temperature decay of thermal plasmas using induction thermal Plasma Irradiation technique Proc. XVIIth Int. Conf. Gas Discharges and their Applications GD2008 pp.89-92 Cardiff UK

[29] Shinsei N, Ishida M, Tanaka Y, Uesugi Y and Ishijima T 2012 Ejection Frequency of Spallation Particles from Polyamide Materials with Water Absorption Irradiated by Ar Thermal Plasma with Molecular Gases Joint Conference of IWHV2012 \& JK 2012 on ED 83 HVE ED-12-122, SP-12-050, HV-12-053 (6pp)

[30] Glaizes A, Razafinimanana M and Vacquie S 1986 Calculation of Thermodynamic Properties and Transport Coefficients for $\mathrm{SF}_{6}-\mathrm{N}_{2}$ Mixtures in the Temperature Range 1,000-30,000 K Plasma Chemistry and Plasma Processing 6(1) 65-78

[31] Andre P and Koalaga Z 2010 Composition of a thermal plasma formed from PTFE with copper in non-oxidant atmosphere. Part I: definition of a test case with the $\mathrm{SF}_{6}$ High Temperature Material Processes (An International Quarterly of High-Technology Plasma Processes) 14(3) pp.279 <hal-00537752>

[32] Nakano T, Tanaka Y, Uesugi Y, Ishijima T, Goto Y and Horibe H 2014 Spallation Occurrence Control by Mixing Phthalate Esters in Polyamide Material for Polymer Ablation Assisted Circuit Breakers Proc. $20^{\text {th }}$ International Conference on Gas Discharges and their Applications pp.215218 Orléans France 
Table 1. Tested polymer materials for the first experiment.

\begin{tabular}{l|cc}
\hline \hline Material & Group & $\begin{array}{c}\text { Decomposition } \\
\text { temperature }[\mathrm{K}]\end{array}$ \\
\hline Poly-Tetra-Fluoro-Ethylene (PTFE) & Thermoplastic & 809 \\
Poly-Ethylene (PE) & Thermoplastic & 734 \\
Poly-Oxy Methylene (POM) & Thermoplastic & 605 \\
Poly-Methyl-Methacrylate (PMMA) & Thermoplastic & 618 \\
Poly-Amide-6 (PA6) & Thermoplastic & 718 \\
Poly-Amide-66 (PA66) & Thermoplastic & 669 \\
Phenol-Formaldehyde (PF) & Thermosetting & - \\
\hline
\end{tabular}


Table 2. Thermal plasma conditions for ICTP experiments

\begin{tabular}{lcccc}
\hline \hline Gas condition & $\begin{array}{c}\mathrm{Ar} \\
{[\mathrm{L} / \mathrm{min}]}\end{array}$ & $\begin{array}{c}\mathrm{N}_{2} \\
{[\mathrm{~L} / \mathrm{min}]}\end{array}$ & $\begin{array}{c}\mathrm{O}_{2} \\
{[\mathrm{~L} / \mathrm{min}]}\end{array}$ & $\begin{array}{c}\text { Input power } \\
{[\mathrm{kW}]}\end{array}$ \\
\hline \hline $100 \% \mathrm{Ar}, 800{ }^{\circ} \mathrm{C}($ Cond. $A)$ & 30 & 0 & 0 & 8.5 \\
$97 \% \mathrm{Ar}+3 \% \mathrm{~N}_{2}($ Cond. $B)$ & 50 & 1.5 & 0 & 12.8 \\
$97 \% \mathrm{Ar}+2 \% \mathrm{~N}_{2}+1 \% \mathrm{O}_{2}\left(\right.$ Cond. $\left.C^{-}\right)$ & 50 & 1.0 & 0.5 & 12.6 \\
$97 \% \mathrm{Ar}+1.5 \% \mathrm{~N}_{2}+1.5 \% \mathrm{O}_{2}($ Cond. $C)$ & 50 & 0.75 & 0.75 & 12.4 \\
$97 \% \mathrm{Ar}+1 \% \mathrm{~N}_{2}+2 \% \mathrm{O}_{2}\left(\right.$ Cond. $\left.C^{+}\right)$ & 50 & 0.5 & 1.0 & 12.2 \\
$97 \% \mathrm{Ar}+3 \% \mathrm{O}_{2}$ (Cond. D) & 50 & 0 & 1.5 & 10.3 \\
\hline \hline
\end{tabular}


Table 3. Mass and thermal energy of $10 \mathrm{~mL}$ air at atmospheric pressure.

\begin{tabular}{c|ccc}
\hline Temperature $(\mathrm{K})$ & Mass $(\mu \mathrm{g})$ & Enthalpy $(\mathrm{J} / \mathrm{g})$ & Thermal energy $(\mathrm{J})$ \\
\hline 5000 & 583 & 102000 & 59.5 \\
7500 & 267 & 327000 & 87.3 \\
10000 & 174 & 478000 & 83.1 \\
12500 & 122 & 683000 & 83.3 \\
15000 & 78 & 1140000 & 88.9 \\
\hline
\end{tabular}


Table 4. Final temperature $T_{\mathrm{f}}$ for each number of spallation particles versus initial temperature of the hot air $T_{\text {air }}$.

\begin{tabular}{c|ccccc}
\hline Initial air temperature & \multicolumn{5}{|c}{ Final temperature $T_{\mathrm{f}}$ for } \\
$T_{\text {air }}(\mathrm{K})$ & 1 particle $(\mathrm{K})$ & 5 ptcls & 10 ptcls & 30 ptcls & 50 ptcls \\
\hline 5000 & 4900 & 4800 & 4700 & 4000 & 3400 \\
7500 & 7400 & 7000 & 6700 & 5500 & 4000 \\
10000 & 9300 & 7700 & 7000 & 5400 & 3900 \\
12500 & 12000 & 9800 & 7500 & 5500 & 3900 \\
15000 & 14400 & 12300 & 9800 & 5700 & 4000 \\
\hline
\end{tabular}




\section{Figure captions}

Figure 1. ICTP torch and chamber.

Figure 2. Specimen shape for water absorption tests and thermal plasma irradiation experiments.

Figure 3. Ar-ICTP irradiation on (b) PTFE, (c) PE, (d) POM, (e) PMMA, (f) PA66, (g) PA6, and (h) PF, (a) is a schematic image.

Figure 4. Structural formulas of (a) PA6 and (b) PA66.

Figure 5. Water retention image of polyamide: (a) normal state and (b) water molecule connected with amide bonds in polyamide which causes water retention of polyamide.

Figure 6. Water absorption ratio of PA6 soaked in pure water at different temperatures for $3 \mathrm{hr}$.

Figure 7. Water absorption ratio of different polymers boiled in hot pure water for 3 hr.

Figure 8. Water absorption ratio of PA6 and PA66 versus soaking time. 
Figure 9. Superimposed image of Ar ICTP irradiation on PA6 and PA66: (a) PA6 without water absorption, (b) PA6 with $6.8 \mathrm{wt} \%$ water absorption, (c) PA66 without water absorption, (d) PA66 with $3.9 \mathrm{wt} \%$ water absorption. The input power to the Ar ICTP is $9.8 \mathrm{~kW}$.

Figure 10. Ablation mass of PA6 / PA66 irradiated by Ar ICTP for $20 \mathrm{s.}$

Figure 11. Dependence of surface temperature of a $\mathrm{TiO}_{2}$ specimen on input power.

Figure 12. Images of $\mathrm{Ar}+\mathrm{N}_{2} / \mathrm{O}_{2}$-ICTP irradiation on water absorbed PA66 captured using a high-speed video camera, (a) $100 \%$ Ar, Condition $A$ in Table 2, (b) $97 \% \mathrm{Ar}+3 \% \mathrm{~N}_{2}$, Condition B, (c) $97 \% \mathrm{Ar}+1.5 \% \mathrm{~N}_{2}+1.5 \% \mathrm{O}_{2}$, Condition C, (d) $97 \% \mathrm{Ar}+3 \% \mathrm{O}_{2}$, Condition D.

Figure 13. Superimposed image of $\mathrm{Ar}+\mathrm{N}_{2} / \mathrm{O}_{2}$-ICTP irradiation on water absorbed PA66, (a) $100 \% \mathrm{Ar}$, Condition $A$ in Table 2, (b) $97 \% \mathrm{Ar}+3 \% \mathrm{~N}_{2}$, Condition B, (c) $97 \% \mathrm{Ar}+1.5 \% \mathrm{~N}_{2}+1.5 \% \mathrm{O}_{2}$, Condition C, (d) $97 \% \mathrm{Ar}+3 \% \mathrm{O}_{2}$, Condition D.

Figure 14. Instantaneous and cumulative number of spallation particles versus time, (a) $100 \% \mathrm{Ar}$, Condition $A$ in Table 2, (b) $97 \% \mathrm{Ar}+3 \% \mathrm{~N}_{2}$, Condition B, (c) $97 \% \mathrm{Ar}+1.5 \% \mathrm{~N}_{2}+1.5 \% \mathrm{O}_{2}$, Condition C, (d) $97 \% \mathrm{Ar}+3 \% \mathrm{O}_{2}$, Condition D.

Figure 15. Cumulative number of spallation particles ejected from $0.9 \mathrm{~s}$ to $1.0 \mathrm{~s}$ for each ICTP condition.

Figure 16. Course of spallation particle ablation in $97 \% \mathrm{Ar}+1.5 \% \mathrm{~N}_{2}+1.5 \% \mathrm{O}_{2}$ ICTP irradiation, (a) $2.482 \mathrm{sec}$, (b) $2.483 \mathrm{sec}$, (c) $2.484 \mathrm{sec,} \mathrm{(d)} 2.485 \mathrm{sec}$.

Figure 17. Ablation mass of $3 \mathrm{wt} \%$ water absorbed PA66 by $20 \mathrm{~s}$ irradiation for each ICTP condition.

Figure 18. Equilibrium composition of air at atmospheric pressure. 
Figure 19. Mass density of air versus the temperature.

Figure 20. Enthalpy of air versus temperature.

Figure 21. Equilibrium composition of mixed vapour consisting of $10 \mathrm{ml}$ air with initial temperature of $10,000 \mathrm{~K}$ and a PA66 spallation particle.

Figure 22. Enthalpy of air-PA66 vapour mixture in cases of the initial temperature of air $10000 \mathrm{~K}$ and $0,1,5,30$, and 50 PA66 particle injection.

Figure 23. Final temperature $T_{\mathrm{f}}$ of air-PA66 vapour versus initial air temperature $T_{\text {air }}$ for each number of spallation particles. 


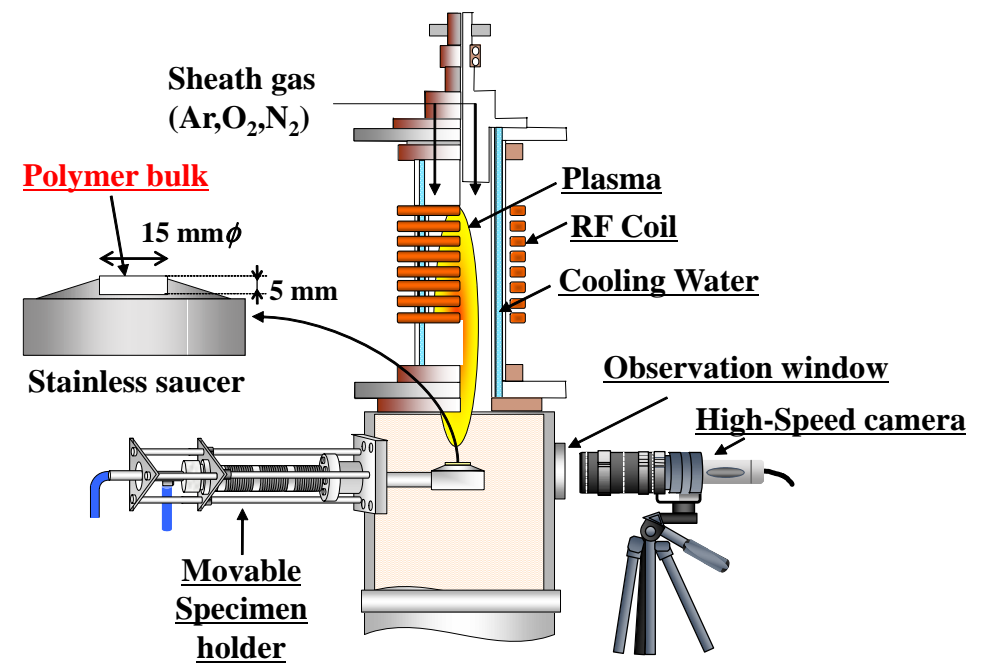

Figure 1. ICTP torch and chamber. 


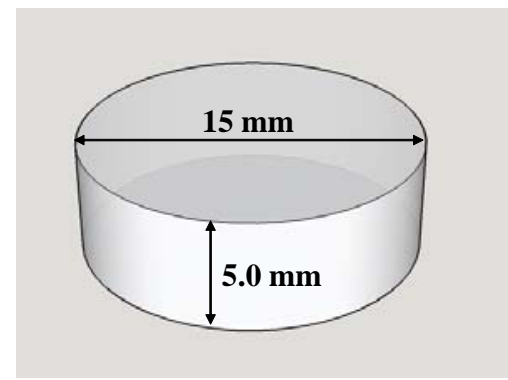

Figure 2. Specimen shape for water absorption tests and thermal plasma irradiation experiments. 


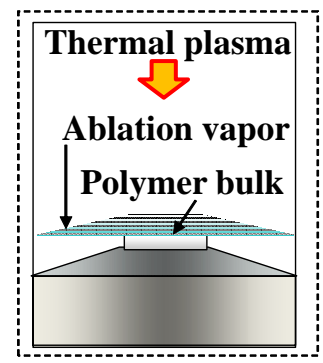

(a) Schematic drawing

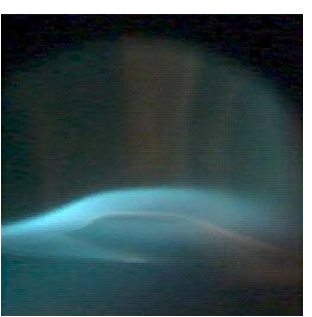

(e) PMMA

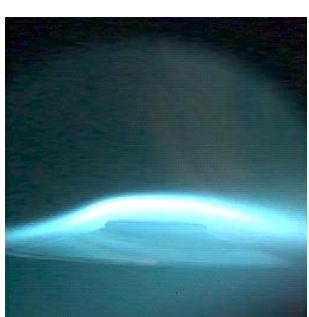

(b) PTFE

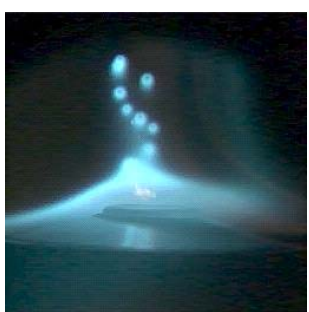

(f) PA6

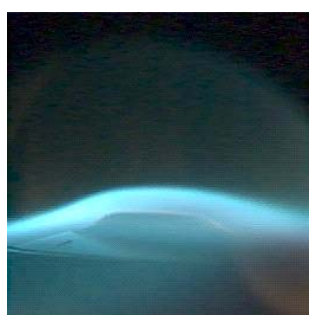

(c) PE

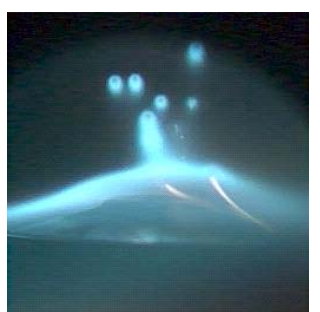

(g) PA66

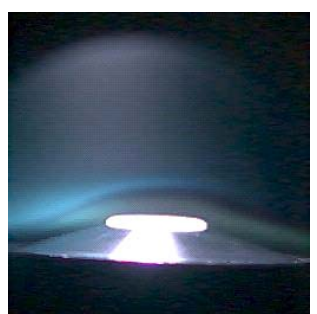

(d) POM

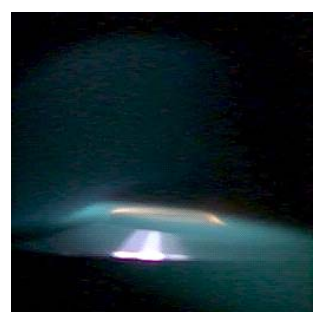

(h) PF

Figure 3. Ar-ICTP irradiation on (b) PTFE, (c) PE, (d) POM, (e) PMMA, (f) PA66, (g) PA6, and (h) PF, (a) is a schematic image. 


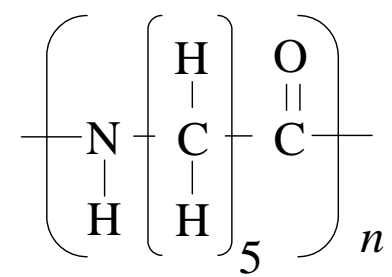

(a) PA6

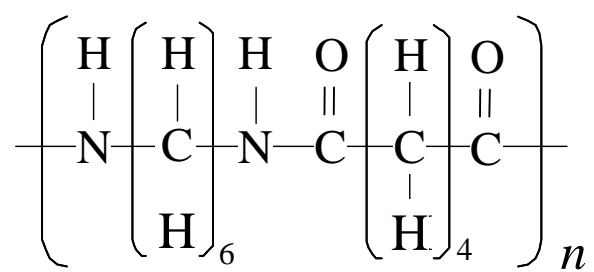

(b) PA66

Figure 4. Structural formulas of (a) PA6 and (b) PA66. 


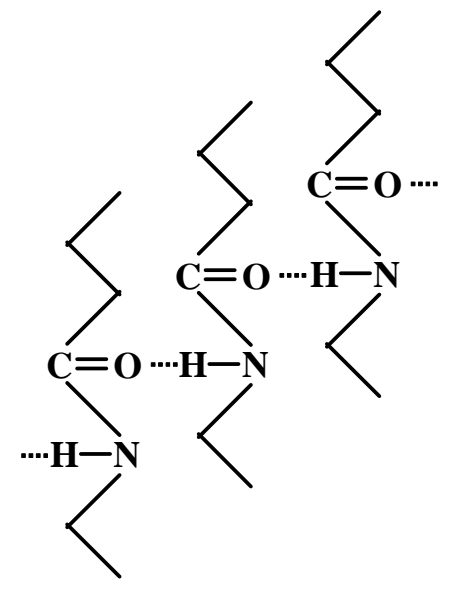

(a) Normal

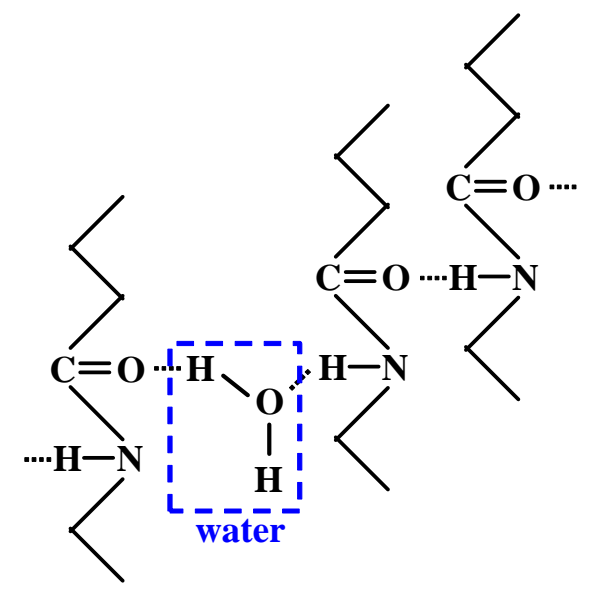

(b) Water retention

Figure 5. Water retention image of polyamide: (a) normal state and (b) water molecule connected with amide bonds in polyamide which causes water retention of polyamide. 


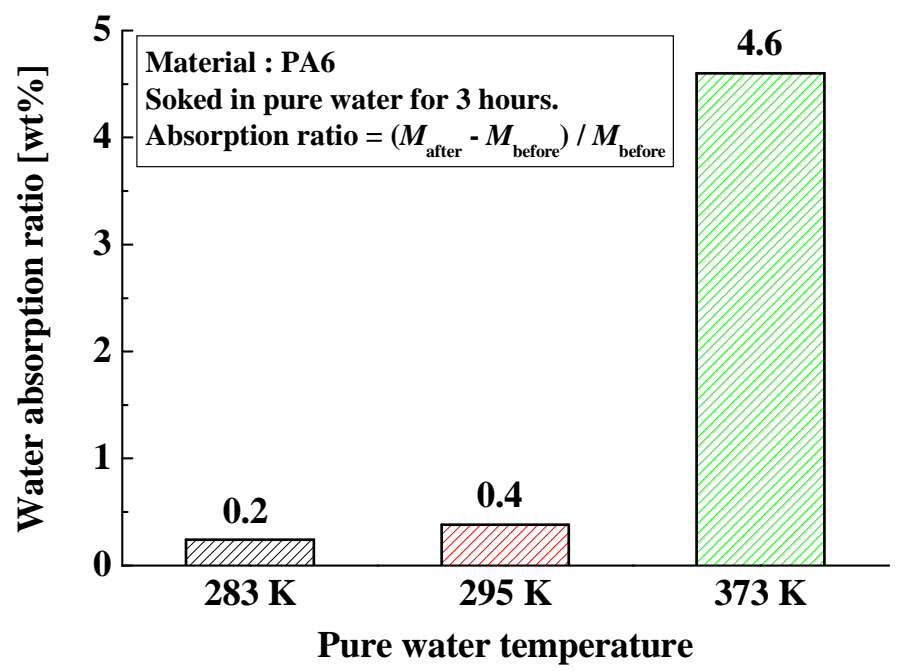

Figure 6. Water absorption ratio of PA6 soaked in pure water at different temperatures for $3 \mathrm{hr}$. 


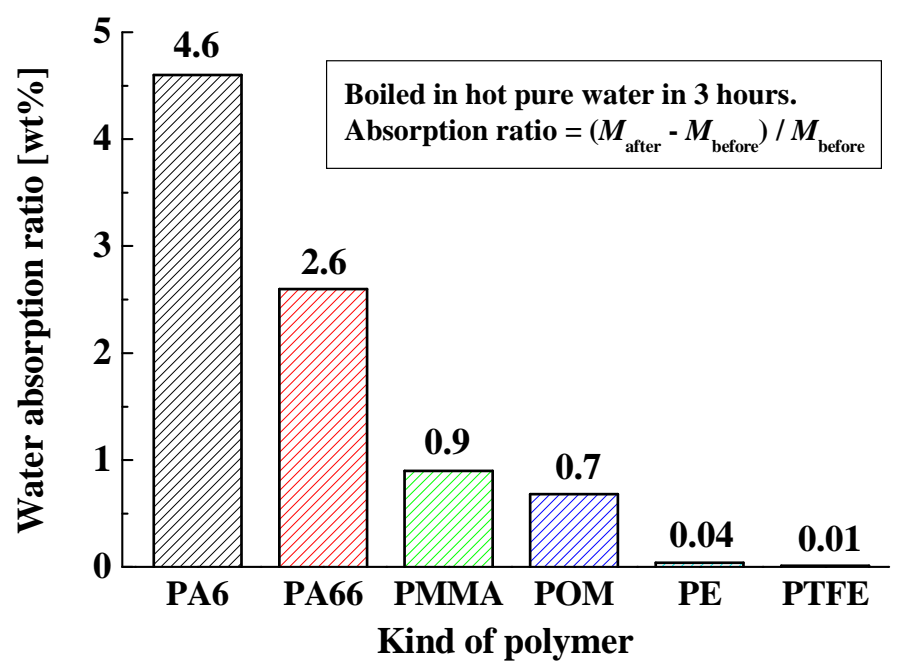

Figure 7. Water absorption ratio of different polymers boiled in hot pure water for 3 hr. 


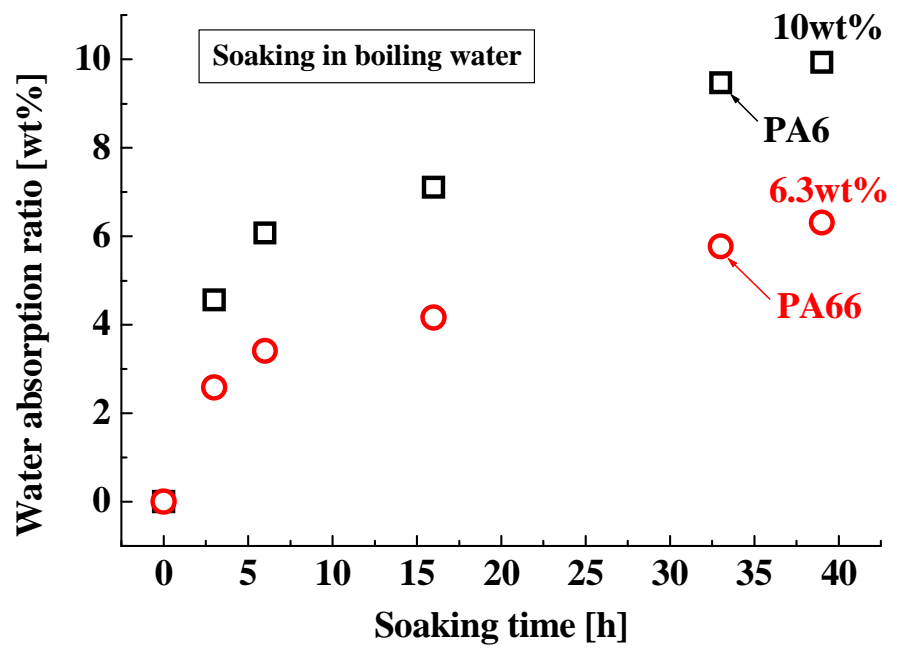

Figure 8. Water absorption ratio of PA6 and PA66 versus soaking time. 


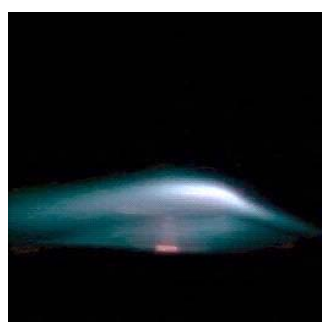

(a) Dry PA6

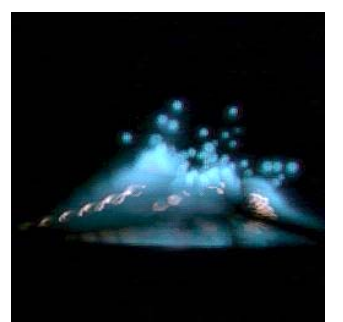

(b) Water PA6

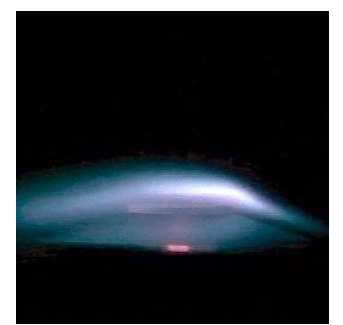

(c) Dry PA66

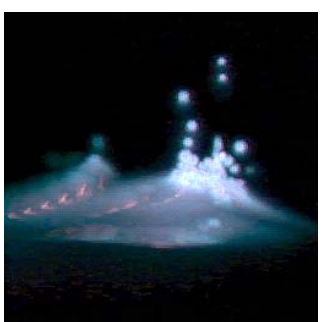

(d) Water PA66

Figure 9. Superimposed image of Ar ICTP irradiation on PA6 and PA66: (a) PA6 without water absorption, (b) PA6 with 6.8 wt $\%$ water absorption, (c) PA66 without water absorption, (d) PA66 with 3.9 wt \% water absorption. The input power to the Ar ICTP is $9.8 \mathrm{~kW}$. 


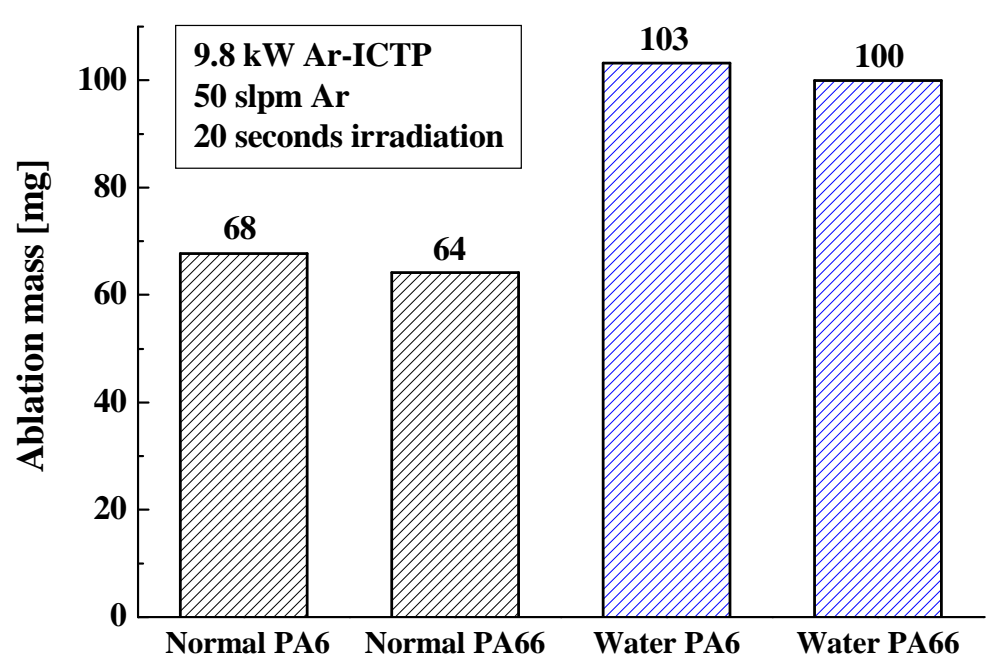

Figure 10. Ablation mass of PA6 / PA66 irradiated by Ar ICTP for $20 \mathrm{~s}$. 


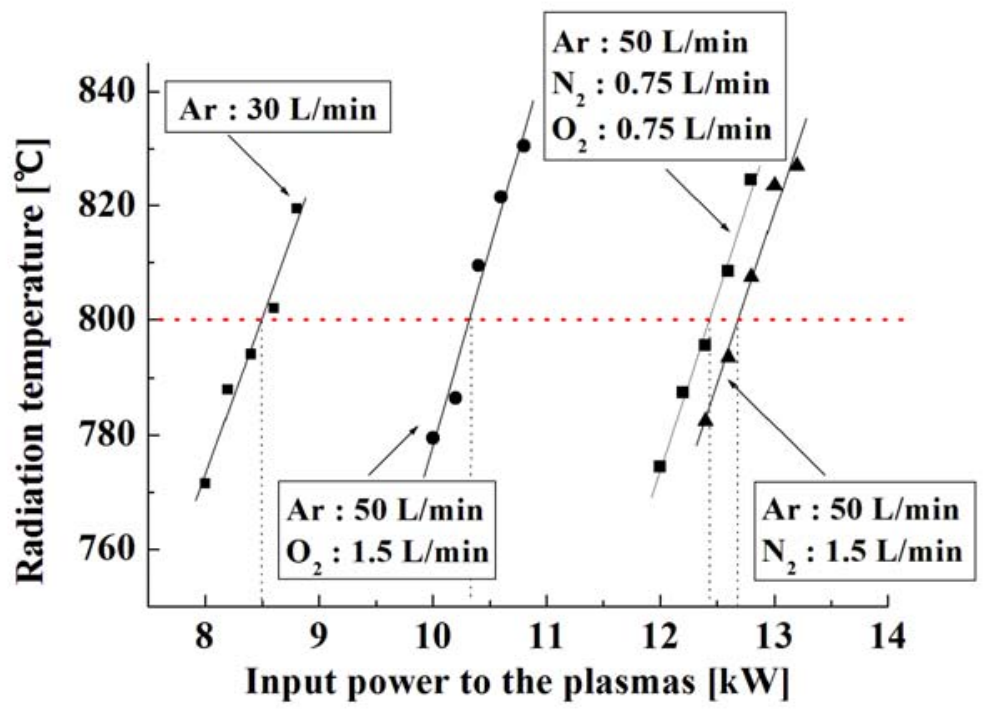

Figure 11. Dependence of surface temperature of a $\mathrm{TiO}_{2}$ specimen on input power. 


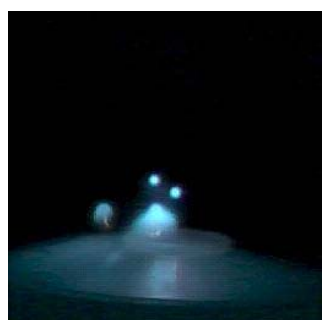

(a) $\mathrm{Ar}$

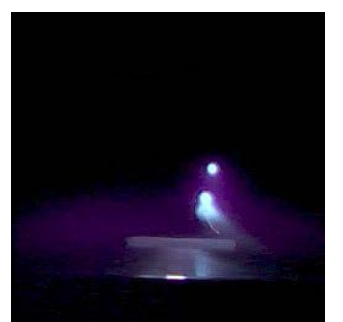

(b) $\mathrm{Ar}+\mathrm{N}_{2}$

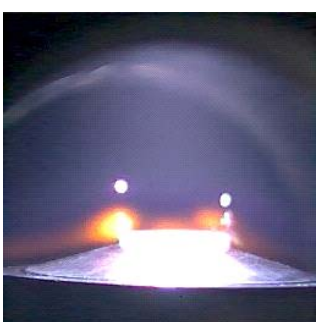

(c) $\mathrm{Ar}+\mathrm{N}_{2}+\mathrm{O}_{2}$

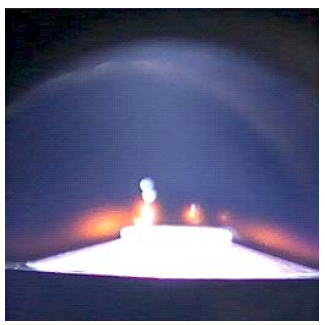

(d) $\mathrm{Ar}+\mathrm{O}_{2}$

Figure 12. Images of $\mathrm{Ar}+\mathrm{N}_{2} / \mathrm{O}_{2}$-ICTP irradiation on water absorbed PA66 captured using a high-speed video camera, (a) $100 \% \mathrm{Ar}$, Condition $A$ in Table 2, (b) $97 \% \mathrm{Ar}+3 \% \mathrm{~N}_{2}$, Condition B, (c) $97 \% \mathrm{Ar}+1.5 \% \mathrm{~N}_{2}+1.5 \% \mathrm{O}_{2}$, Condition C, (d) $97 \% \mathrm{Ar}+3 \% \mathrm{O}_{2}$, Condition D. 


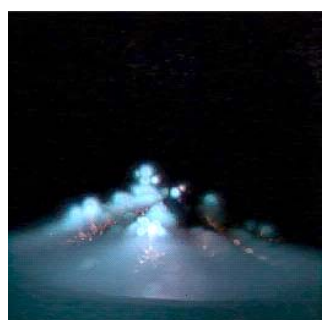

(a) $\mathrm{Ar}$

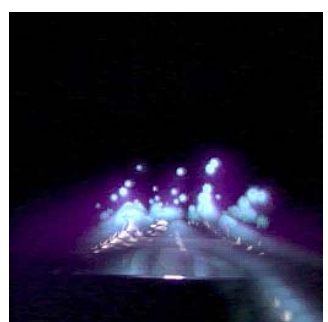

(b) $\mathrm{Ar}+\mathrm{N}_{2}$

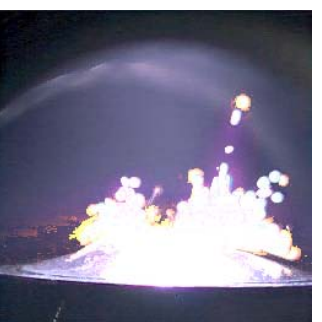

(c) $\mathrm{Ar}+\mathrm{N}_{2}+\mathrm{O}_{2}$

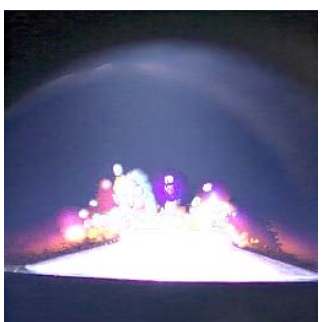

(d) $\mathrm{Ar}+\mathrm{O}_{2}$

Figure 13. Superimposed image of $\mathrm{Ar}+\mathrm{N}_{2} / \mathrm{O}_{2}$-ICTP irradiation on water absorbed PA66, (a) $100 \% \mathrm{Ar}$, Condition $A$ in Table 2, (b) $97 \% \mathrm{Ar}+3 \% \mathrm{~N}_{2}$, Condition B, (c) $97 \% \mathrm{Ar}+1.5 \% \mathrm{~N}_{2}+1.5 \% \mathrm{O}_{2}$, Condition C, (d) $97 \% \mathrm{Ar}+3 \% \mathrm{O}_{2}$, Condition D. 


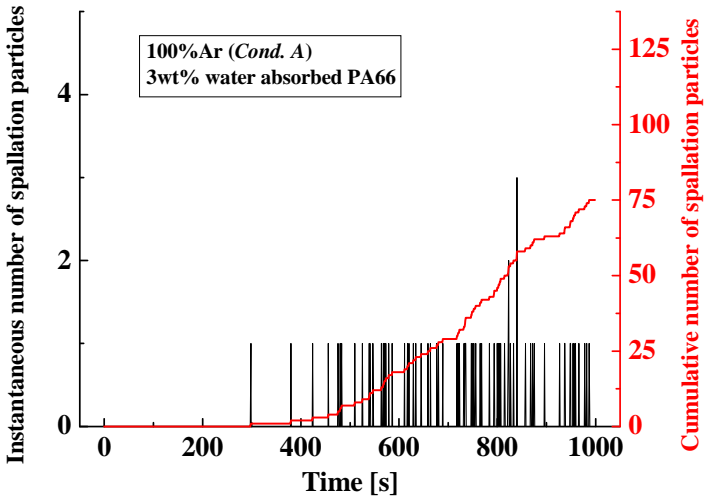

(a) $\mathrm{Ar}$

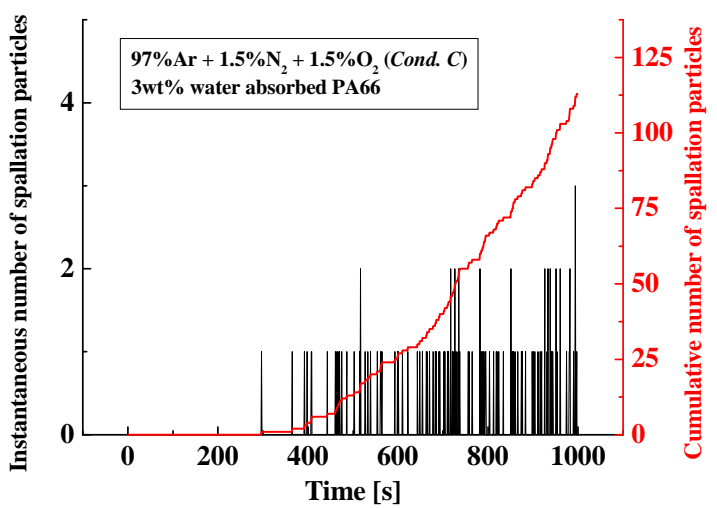

(c) $\mathrm{Ar}+\mathrm{N}_{2}+\mathrm{O}_{2}$

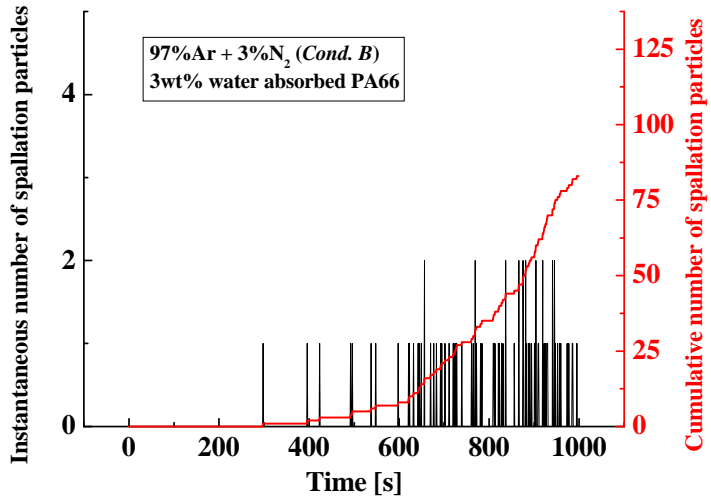

(b) $\mathrm{Ar}+\mathrm{N}_{2}$

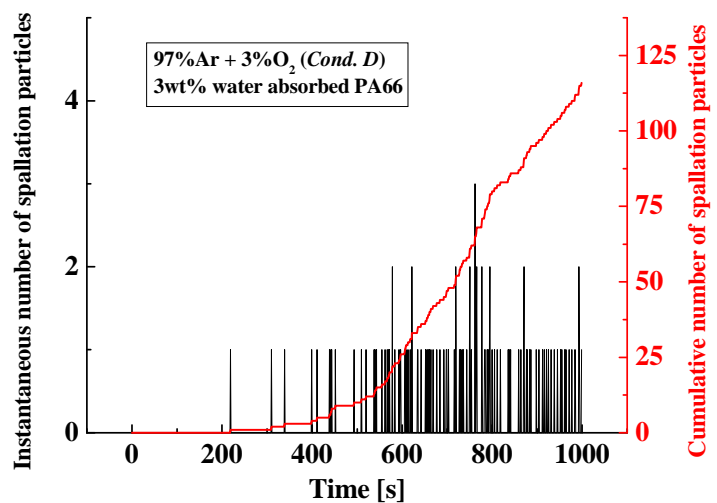

(d) $\mathrm{Ar}+\mathrm{O}_{2}$

Figure 14. Instantaneous and cumulative number of spallation particles versus time, (a) $100 \% \mathrm{Ar}$, Condition $A$ in Table 2, (b) $97 \% \mathrm{Ar}+3 \% \mathrm{~N}_{2}$, Condition B, (c) $97 \% \mathrm{Ar}+1.5 \% \mathrm{~N}_{2}+1.5 \% \mathrm{O}_{2}$, Condition $C$, (d) $97 \% \mathrm{Ar}+3 \% \mathrm{O}_{2}$, Condition $D$. 


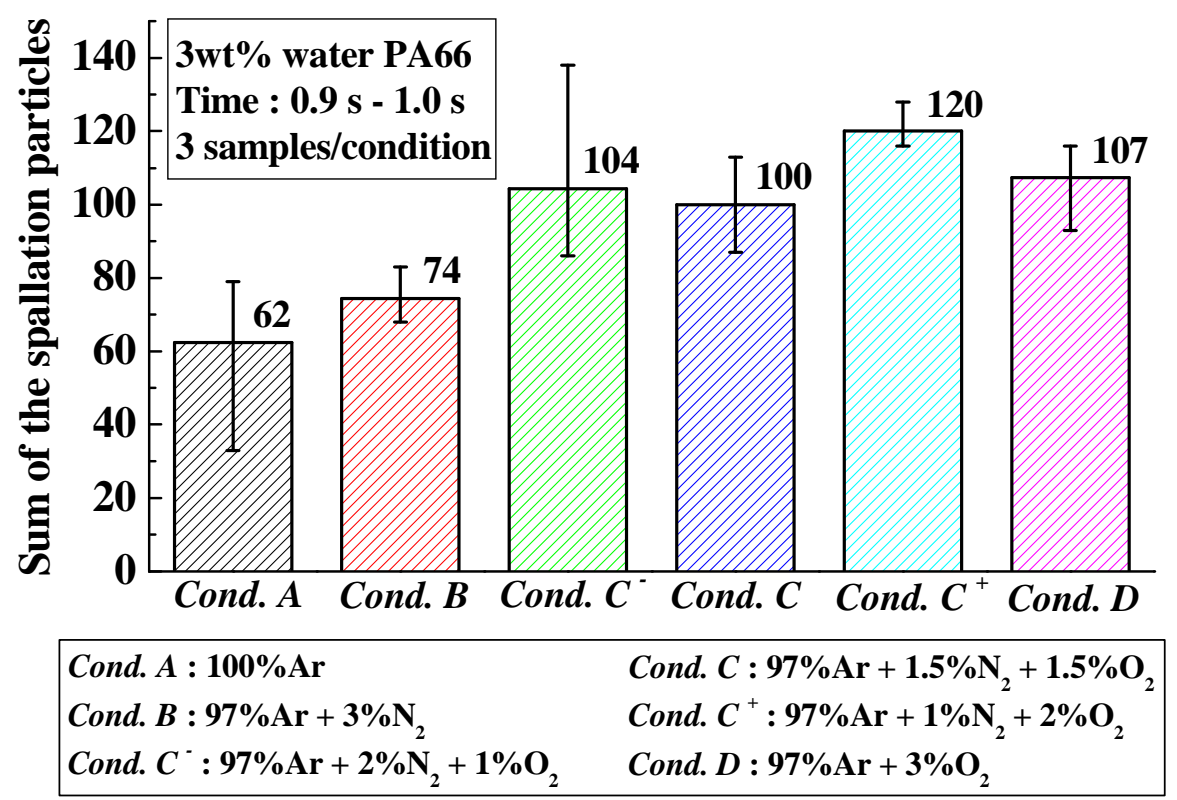

Figure 15. Cumulative number of spallation particles ejected from $0.9 \mathrm{~s}$ to $1.0 \mathrm{~s}$ for each ICTP condition. 


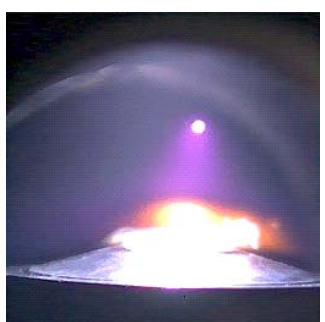

(a) $2.482 \mathrm{sec}$

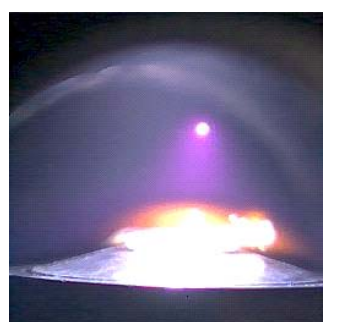

(b) $2.483 \mathrm{sec}$

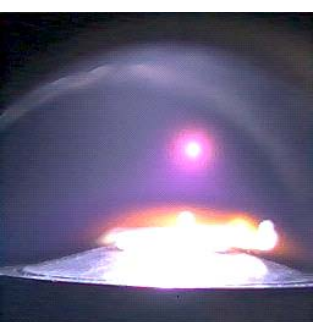

(c) $2.484 \mathrm{sec}$

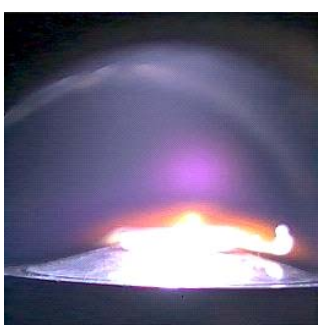

(d) $2.485 \mathrm{sec}$

Figure 16. Course of spallation particle ablation in $97 \% \mathrm{Ar}+1.5 \% \mathrm{~N}_{2}+1.5 \% \mathrm{O}_{2} \mathrm{ICTP}$ irradiation, (a) $2.482 \mathrm{sec}$, (b) $2.483 \mathrm{sec}$, (c) $2.484 \mathrm{sec}$, (d) $2.485 \mathrm{sec}$. 


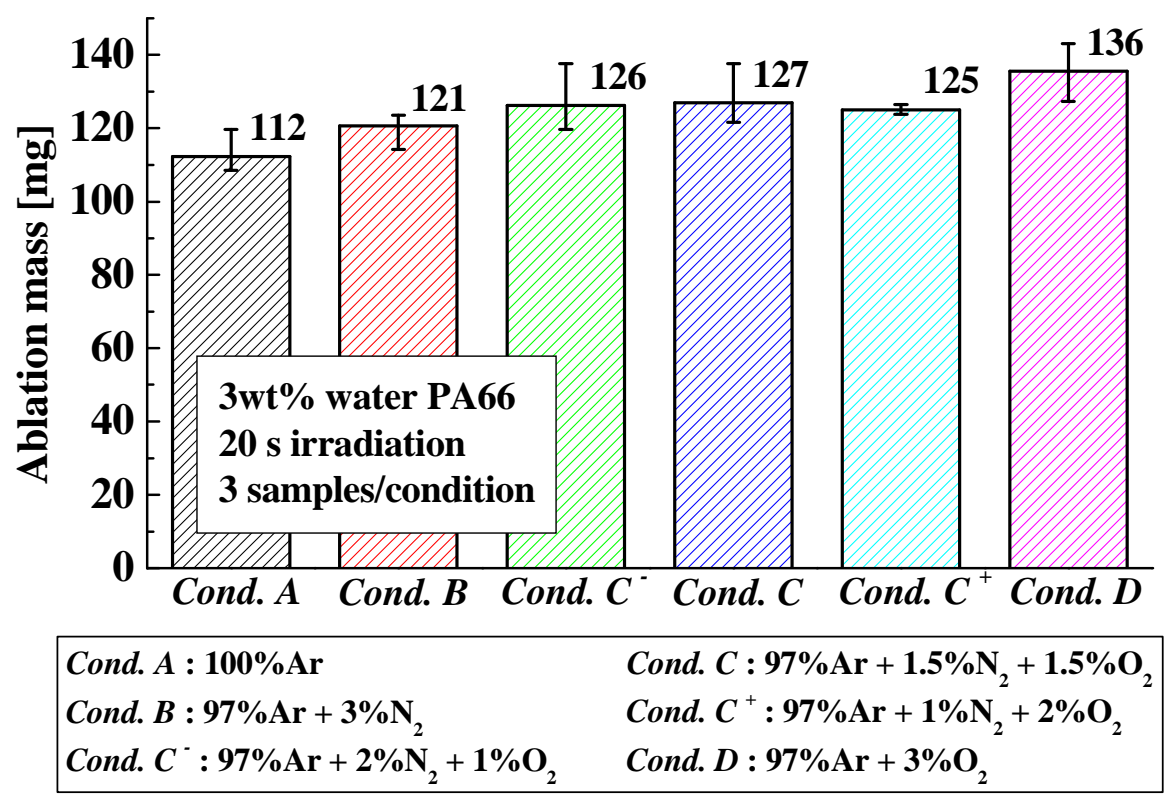

Figure 17. Ablation mass of 3wt\% water absorbed PA66 by 20 s irradiation for each ICTP condition. 


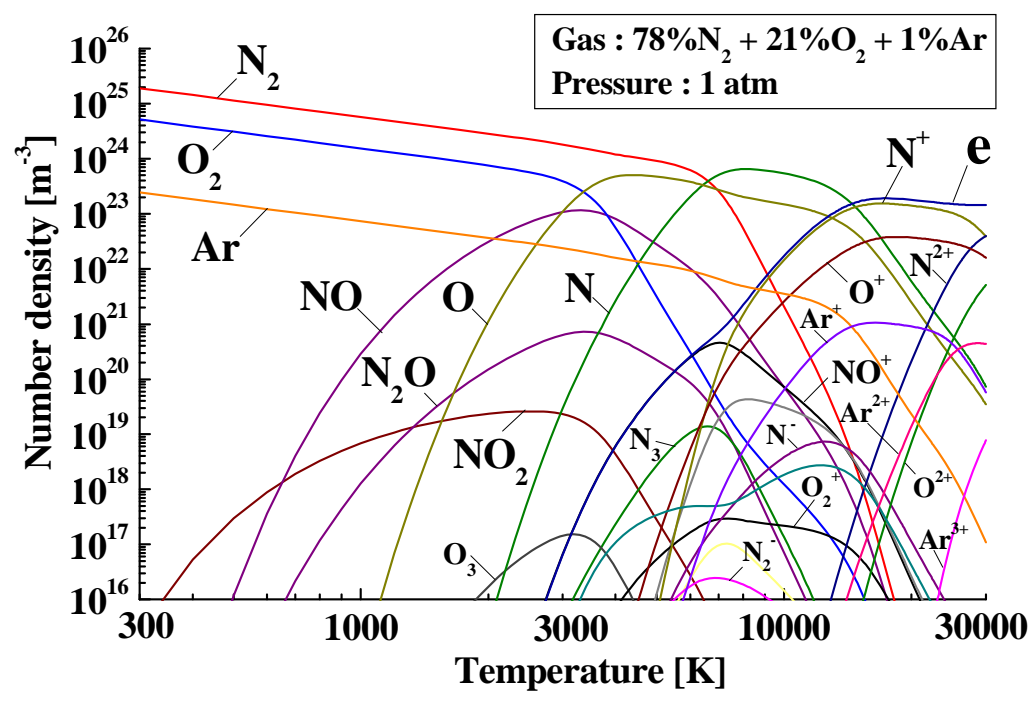

Figure 18. Equilibrium composition of air at atmospheric pressure. 


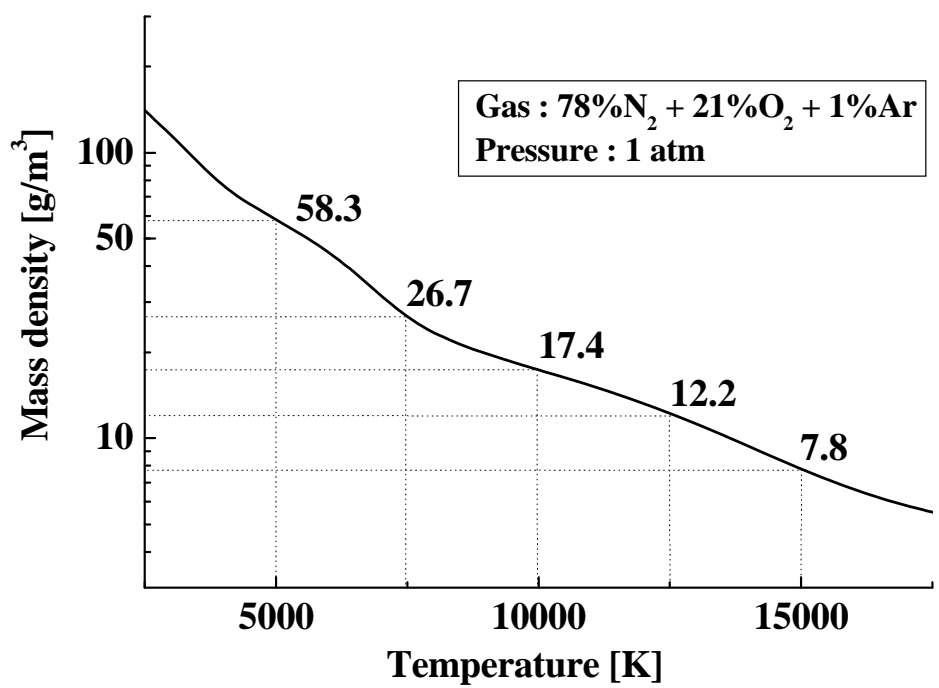

Figure 19. Mass density of air versus the temperature. 


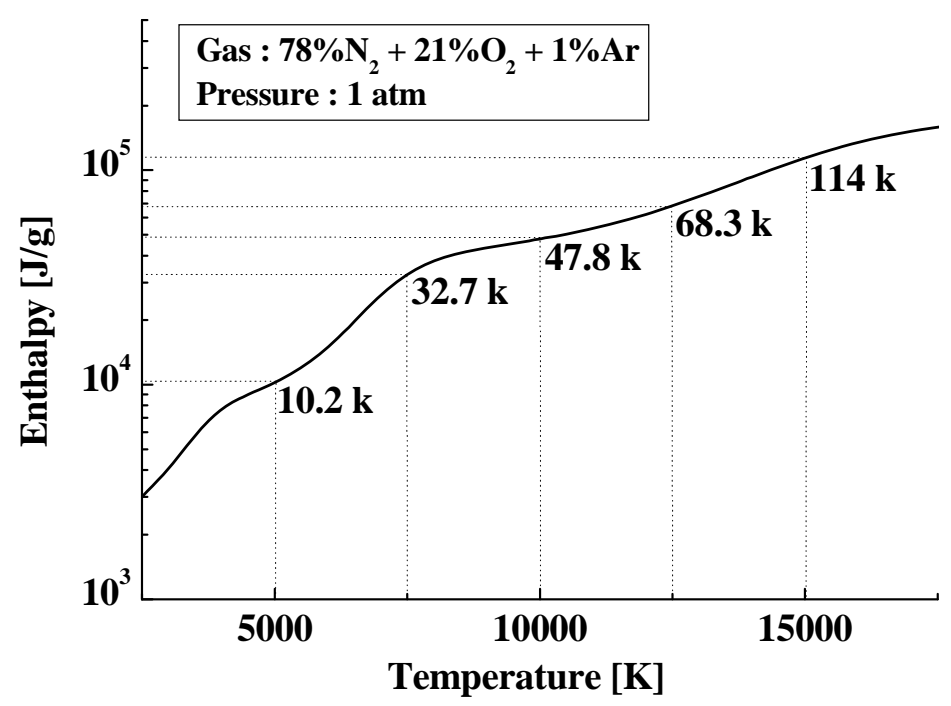

Figure 20. Enthalpy of air versus temperature. 




Figure 21. Equilibrium composition of mixed vapour consisting of $10 \mathrm{ml}$ air with initial temperature of $10,000 \mathrm{~K}$ and a PA66 spallation particle. 


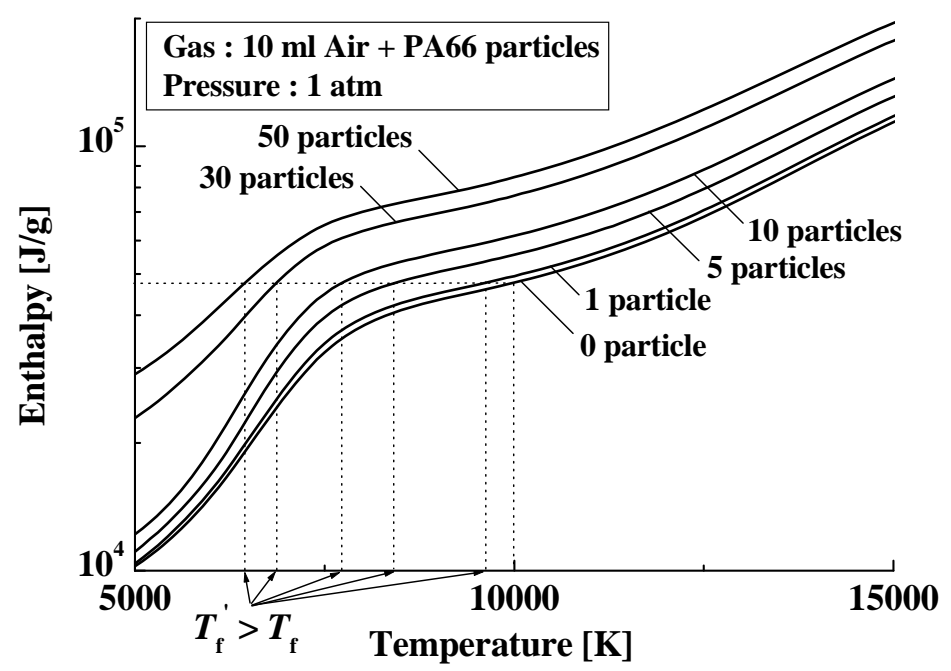

Figure 22. Enthalpy of air-PA66 vapour mixture in cases of the initial temperature of air $10000 \mathrm{~K}$ and $0,1,5,30$, and 50 PA66 particle injection. 


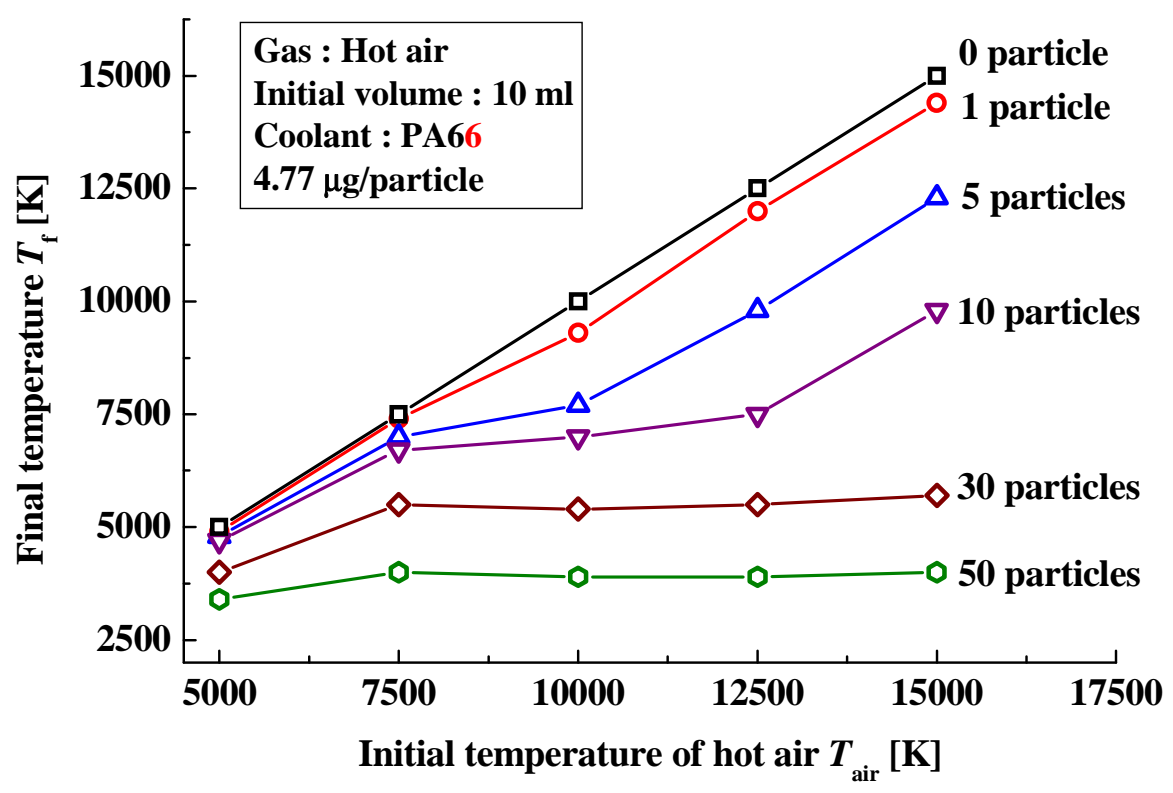

Figure 23. Final temperature $T_{\mathrm{f}}$ of air-PA66 vapour versus initial air temperature $T_{\text {air }}$ for each number of spallation particles. 